Revista Oficial del Poder Judicial

ÓRGANO DE INVESTIGACIÓN DE LA CORTE SUPREMA DE JUSTICIA DE LA REPÚBLICA DEL PERÚ

Vol. 9, n. 11, enero-junio, 2019, 355-438

ISSN versión impresa: 1997-6682

ISSN versión electrónica: 2663-9130

DOI: https://doi.org/10.35292/ropj.u9i11.12

\title{
¿Ser o no ser del Poder Judicial? Aproximación bibliográfica sobre el proceso de reforma, modernización, reestructuración y refundación de la judicatura nacional
}

To be or not to be of The Judiciary?

Bibliographic approach on the process of reform, modernization, restructuring and refounding

of the national judiciary

0 (이

HELDER DOMÍNGUEZ HARO

Centro de Investigaciones Judiciales del Poder Judicial

(Lima, Perú)

Contacto: hdominguez@pj.gob.pe

https://orcid.org/0000-0003-4617-8341

\section{RESUMEN}

El presente trabajo identifica, desde el ángulo bibliográfico, los diferentes aportes, propuestas, enfoques y estudios en torno a la reforma de la impartición de justicia en el Perú o llamada también modernización, reestructuración o refundación del Poder Judicial. 
No obstante la numerosa bibliografía sobre tan importante tema, se da cuenta de un núcleo interesante de publicaciones correspondientes al siglo XX e inicios de la presente centuria. Un primer repaso bibliográfico para promover la investigación sobre la judicatura peruana y entender su devenir histórico antecede a un oportuno análisis del autor sobre la necesidad de un cambio desde el mismo Poder Judicial, circunscrito a una teoría democrática para la gobernabilidad judicial, y que involucra la participación de los diferentes actores del sistema de justicia y de la sociedad civil, por un Poder Judicial sólido y predecible como sustento de la democracia constitucional.

Palabras clave: Poder Judicial, bibliografía, reforma, modernización, reestructuración, refundación, democracia constitucional, gobernabilidad judicial.

\section{ABSTRACT}

This work identifies, from the bibliographic point of view, the different contributions, proposals, approaches and studies around the reform of the administration of justice in Peru, also called modernization, restructuring or refounding of the Judiciary. Notwithstanding the wide bibliography on this important subject, an interesting nucleus of publications corresponding to the 20th century and the beginning of the present century is reported. A first bibliographical review to promote research on the Peruvian judiciary and understand its historical evolution precedes a timely analysis of the author on the need for a change from the Judiciary itself, circumscribed to a democratic theory for judicial governance, and involves the participation of the different actors of the justice system and civil society, by a solid and predictable Judiciary as a support for constitutional democracy. 
Key words: The Judiciary, bibliography, reform, modernization, reconstruction, refounding, constitutional democracy, judicial governance.

Recibido: 10/05/2019 Aceptado: 10/06/2019

\section{PRECISIONES: PENSAR LA JUSTICIA}

Las ideas que se articulan en el presente artículo no pretenden ser innovadoras ante una cuestión recurrente, compleja y largamente estudiada como es el Poder Judicial o, como se suele llamar con mayor frecuencia, la reforma del Poder Judicial.

Se intenta abordar la tan apetecida reforma judicial recreando ideas sobre esta, congruentes con las exigencias de la época de perfil posmoderno. Se pretende bosquejar, sintéticamente, el proceso histórico de su desarrollo y estado actual, teniendo en cuenta algunos rasgos significativos a la luz de fuentes bibliográficas mínimas dentro del universo existente.

Como premisa mayúscula se debe considerar que cuando se menciona la reforma del Estado peruano, se debe entender como un proceso que abraza la reforma de los poderes u órganos públicos; y, según sea el caso, de los órganos autónomos constitucionales, los llamados extrapoderes en clave sagüesiana. En consecuencia, analizar el problema del Poder Judicial es escudriñar la problemática estatal o, en otras palabras, la reforma del Estado también lleva consigo la reforma judicial.

Tamaña situación involucra la idea medular de que si el Estado es el marco de la sociedad en cuyo seno se encuentra la comunidad de jueces, su viabilidad va de la mano, qué duda cabe, con un sistema democrático de construcción constitucional. El fenómeno democrático debe aflorar en todas partes o sectores de la sociedad (valores democráticos en la familia, cultura, economía, política, 
etc.), apostando por optimizar el ejercicio de las libertades para el desenvolvimiento libre en justicia de las gentes.

Sobre la reforma judicial peruana se ha escrito muchísimo, en demasía y de toda envergadura, ya sea en términos macro y sobre determinados y puntuales temas - piénsese en excelentes trabajos por especialidad sobre reforma penal, civil, comercial, despacho judicial, problemática de los reos en cárcel, entre otros-. Y como proceso histórico ha recibido diversos nombres o etiquetas de acuerdo con cada época, preferentemente reforma y modernización, y después se ha venido utilizando expresiones como reestructuración y refundación en el siglo XXI ${ }^{1}$. De lo que se trata es de resumir de modo preliminar algunas ideas fuerza como insumos ante la gesta de la nueva reforma judicial y política que se está viviendo.

\section{ENFOQUE DEMOCRÁTICO CONSTITUCIONAL DEL PODER JUDICIAL: ¿UN PODER SIN PODER?}

La democracia constitucional proporciona los elementos de justificación de los poderes judiciales, pues su contenido esencial se circunscribe a un mundo "con» Constitución y «con» derechos; y tal contenido de juridificación de la democracia tiene como fuentes

1 Sobre la base de los discursos de inicio del año judicial de un nuevo presidente del Poder Judicial, se ha identificado en el siglo XXI todos los usos posibles: reforma (Mario Urrelo 2001, Humberto Vásquez 2005, Francisco Távara 2007, Javier Villa Stein 2009, Enrique Mendoza 2013, Víctor Ticona 2015, Duberlí Rodríguez 2017 y José Luis Lecaros 2019), modernización (Mario Urrello 2001, Óscar Alfaro 2002, Hugo Sivina 2003, César San Martín 2011, Enrique Mendoza 2013, Duberlí Rodríguez 2017 y José Luis Lecaros 2019), reestruturación (Francisco Távara 2007 y Víctor Ticona 2015; y de uso frecuente en el mandato del Dr. Hugo Sivina no obstante no haber estado en el texto de su discurso), refundación (Hugo Sivina 2003 y Víctor Ticona 2005) y cambio judicial (César San Martín 2011, José Luis Lecaros 2019. Y dada la crisis del sistema judicial producto de los CNM audios, asumió la Presidencia del Poder Judicial, el Dr. Víctor Prado, quien en su mensaje por el Día del Juez, 2018, evocó el término cambio estructural). 
explícitas la constitucionalización del derecho y la teoría integral y dinámica del derecho. La democracia, llámese constitucional, es un principio legitimador, es el marco donde se despliega el conjunto de derechos humanos garantizados y su notoria relación con los poderes públicos. Esta tiene en la fuerza normativa de la Constitución, los valores y principios constitucionales, su punto de inicio y de llegada ${ }^{2}$. Estamos ante un paradigma constitucional en expansión, el cual debe al profesor Luigi Ferrajoli su desarrollo pormenorizado, al igual que al jurista Perfecto Andrés Ibáñez su extraordinaria labor de difusión y debate intercontinental. No es casual que estemos hablando de dos distinguidos exjueces europeos estudiosos del fenómeno democrático y su relación con la judicatura ordinaria y constitucional ${ }^{3}$.

Se está construyendo una teoría democrática de la judicatura, para una justicia democrática centrada en la persona y el ciudadano; en otros términos, un pensamiento judicial acorde con un Estado democrático-constitucional, cuya línea sustantiva es el compromiso de lo judicial con la plena vigencia y garantía de los derechos humanos, los derechos ciudadanos, la seguridad jurídica, la sociedad, la cultura, la transparencia, el crecimiento y el desarrollo

2 Domínguez Haro, Helder (2018). Democracia constitucional. Elementos teóricos, desarrollo jurisprudencial e introducción bibliográfica. Lima: Grijley, 65-ss. La tendencia que aboga la prevalencia de una democracia constitucional fue iniciada por el Tribunal Constitucional peruano desde inicios del corriente siglo a nivel jurisprudencial, y en el Perú de hoy se suma el Jurado Nacional de Elecciones.

3 De los muchos libros del intelectual italiano Ferrajoli destacan especialmente su Teoría del garantismo penal (1989) y Principia iuris. Teoría del derecho y de la democracia, 3 tomos (2007). Del mismo autor, la prestigiosa editorial Trotta ha publicado recientemente un nuevo libro: Los derechos y sus garantías. Conversación con Mauro Barberis (2016), que constituye una interesante y ejemplar conversación y ejercicio de interlocución entre dos intelectuales de alto nivel como son Ferrajoli y Barberis, en cuestiones nucleares, polémicas y de actualidad, como sucede con el tercer bloque de la obra dedicado a la democracia y a la política. Por su parte, el español Perfecto Andrés Ibáñez ha escrito Cultura constitucional de la jurisdicción (2010), solo para citar una de sus diversas publicaciones. 
económico. Al respecto, los estudios sobre la administración de justicia dan cuenta de que su inadecuado funcionamiento es un serio freno para el desarrollo económico, político y social del país. El Banco Mundial ha indicado en su momento que el sistema judicial repercute de un modo considerable en la riqueza de un país ${ }^{4}$ o el sistema de justicia es un factor que debe considerarse en el crecimiento de la productividad de un país ${ }^{5}$. El hecho de que exista una conexión directa entre el sistema de justicia con la productividad, no quiere decir que la justicia se reduzca a un determinismo económico o a una simple fórmula cuantitativa. Ello significa reconocer que un sistema jurídico eficiente maximiza el uso racional de los escasos recursos y reduce al mínimo los costos para una mejor satisfacción de las necesidades humanas ${ }^{6}$.

La democracia de arquitectura constitucional significa una relación de paridad y control de los poderes públicos, poderes

4 Banco Mundial (2006). Where is the Wealth of Nations? Measuring Capital for the 21st Century. Working Paper n. ${ }^{\circ}$ 14. Washington, D. C.: Banco Mundial.

5 Importa la lectura del primer Informe de Competitividad 2019 elaborado por el Consejo Privado de Competitividad (CPC), creado por el Instituto Peruano de Administración de Empresas (IPAE), que desarrolla siete de catorce factores que explican el crecimiento de la productividad, uno de ellos es el sistema de justicia. Se propone un diagnóstico, se identifican los problemas y se plantean propuestas de solución; y no obstante los puntos de vista que de hecho genera, es un documento de trabajo abierto al debate público (https://www.ipae.pe/wp-content/ uploads/2018/12/Informe-CPC.pdf).

6 Al respecto, el Poder Judicial peruano tiene clara la conexión del sistema judicial con el crecimiento económico y el bienestar nacional. A guisa de ejemplo, en el 2013 la judicatura nacional participó del Proyecto de Mejoramiento de los Sistemas Judiciales para el Comercio y la Economía, que contó con el concurso de la Oficina del Comisionado para Asuntos Federales de la Judicatura de Canadá; y en el 2016 se formó la Comisión de Trabajo encargada de coordinar las acciones, actividades e iniciativas vinculadas a la participación del Poder Judicial del Perú y la Organización para la Cooperación y el Desarrollo Económico (OCDE) en el marco del Acuerdo y la Carta de Entendimiento relativo al Programa País. Dos importantes experiencias en las cuales participé al formar parte de las comisiones que se crearon para tales propósitos. 
en un mismo nivel y equilibrados para garantizar el respeto de la dignidad y los derechos de los seres humanos, de los ciudadanos. En esa lógica, impartir justicia es dotar primariamente a los jueces de un poder no menos importante $y$, en consecuencia, ningún poder del Estado es el «primer», «segundo» o «tercer» poder o «poder de tercera».

El jurista y juez del Tribunal Europeo de Derechos Humanos Luis López Guerra ${ }^{7}$ ha indicado con toda pulcritud que si el siglo XIX fue el siglo del Legislativo a través de una importante legislación traducida en códigos civiles, comerciales, de procedimiento; y la mayor parte del siglo XX el del Poder Ejecutivo, parece haberse avanzado hacia una fase en que le corresponde un esencial protagonismo al Poder Judicial, en tanto encargado de garantizar y proteger las situaciones creadas por la continua evolución de los regímenes constitucionales, y como encargado de garantizar y proteger los derechos de las personas.

Un dato capital demasiado relevante de la historia del pensamiento universal sobre la democracia es su identificación con el binomio Ejecutivo-Parlamento $y$, posteriormente, con la jurisdicción ordinaria y constitucional (cortes de justicia, cortes o tribunales constitucionales). En efecto, si bien los diversos esquemas teóricos sobre la experiencia democrática han contribuido a la formación de su definición y contenido, teniendo como referente el principio de la separación o división de poderes (ya sea apostando por su consagración, crítica y replanteamiento), falta recorrer y acentuar el estudio democrático de uno de los poderes constitucionales llamado Poder Judicial.

7 López Guerra, Luis (2001). El Poder Judicial en el Estado Constitucional. Lima: Palestra, 34. Corresponde también a inicios del siglo XXI el estudio de Monroy GÁlvez, Juan (2003). «De la administración de justicia al Poder Judicial. ¿Cambiando de oxymoron?». Cuadernos de Política Judicial, 1, 23-60. 
Tal aseveración obedece a la forma como se entendió a la judicatura desde sus inicios. Históricamente, la existencia de la función jurisdiccional o la llamada «administración de justicia» de sus inicios y no como un poder del Estado. Recuérdese que para el inglés Locke lo judicial no era poder y si bien el francés Montesquieu formalmente identifica al aparato judicial como un poder, su mirada se centraba en el poder político concentrado en el Ejecutivo y en el Legislativo. En efecto, el principio liberal e histórico de división de poderes no contemplaba en sus inicios al Poder Judicial, considerado como un ente administrativo que se encargaba precisamente de «administrar justicia» o una actividad o facultad administrativa para resolver los conflictos intersubjetivos.

Ese tránsito de la administración de justicia por impartición de justicia como auténtico Poder Judicial es consecuencia del constitucionalismo democrático. Es un hito significativo -o ruptura, como dicen los historiadores- para comprender la naturaleza de la función judicial, como una expresión de la potestad estatal de impartir justicia, que proviene del poder ciudadano, de la sociedad en su conjunto, y allí radica su legitimidad social y democrática. Y no podría ser de otro modo, por cuanto el Poder Judicial, a través de sus diferentes órganos jurisdiccionales, aplica el derecho - que recae sin intermediarios- sobre las personas, ciudadanos, y afecta sus bienes, sus propiedades, su libertad y su honor o incluso su propia vida.

En efecto, investido de imperio y jurisdicción, el juez es el depositario de la función del Estado para impartir justicia; es decir, la función jurisdiccional que le ha sido conferida a la judicatura no se deriva de un poder abstracto, sino que se encuentra referida al conocimiento de casos concretos en los cuales el ejercicio de la jurisdicción corresponde a todos los jueces, que son a su vez garantes de la transparencia de los poderes públicos frente a sus actos ilícitos. La judicatura como poder constitucional constituido -que emana del pueblo- tiene la potestad jurisdiccional de hacer 
eficaz el derecho objetivo, ya sea resolviendo conflictos, eliminando incertidumbres, controlando la actuación administrativa de los órganos del Estado, o en blanco y negro: «controlando a los otros poderes».

Siguiendo ese orden esbozado, el Texto Fundamental peruano de 1993 - interpretado - reconoce la calidad de poder a la judicatura, no como algo lírico sino tangible y presente. Dentro de un Estado constitucional o Estado constitucional y democrático de derecho, el Poder Judicial, como poder legítimo y constituido, es y debe ser un garante de la tutela de los derechos constitucionales y de la sujeción de los poderes públicos a la Constitución y la ley (principio de constitucionalidad y legalidad). Si bien el constitucionalismo peruano iniciado con la moderna Carta Política de 1979 hechiza una judicatura, por lo menos mejor que las Constituciones anteriores, con tendencias propias de un poder público: «históricamente el Poder Judicial hasta la Constitución de 1979, fue una dependencia del Ministerio de Justicia y su presupuesto se encontraba incluido como una partida más de dicho portafolio. Un habilitado venía cada mes a pagar a los magistrados de todas las categorías. Y dice un viejo refrán que "quien paga manda" $»^{8}$. Sin embargo, dicha tendencia en cuanto a la autonomía en lo económico del quehacer judicial es jaqueada por la Constitución de 1993. Es por ello que para superar esa situación, se ha indicado que la Constitución actual debe ser «interpretada» en función de una interpretación institucional y sistemática desde la vertiente democrática, y alimentada del constitucionalismo contemporáneo.

Las reflexiones antes vertidas nos permiten señalar que en un contexto de democracia constitucional el poder jurisdiccional de los jueces no puede ser arbitrario, por cuanto el fundamento

8 Discurso del señor presidente de la Corte Suprema de Justicia de la República doctor don Juan Vicente Ugarte del Pino, en la ceremonia de apertura del año judicial de 1987. Publicación oficial. Lima, página 14. 
democrático del deber de motivar las decisiones jurisdiccionales en los diferentes niveles, es un ingrediente consustancial propio de un sistema de justicia acorde con reglas del buen gobierno democrático. Se busca además que las resoluciones judiciales debidamente motivadas sean predecibles necesariamente ${ }^{9}$, y son los diferentes plenos jurisdiccionales a nivel supremo (desde el 2005) y a escala superior (en efecto, iniciados en la década de los noventa y de regularidad y vocación de permanencia en la práctica a partir del presente siglo) los que apuntan a la uniformidad de los fallos judiciales en el Perú. En los últimos diez años, el conjunto de acuerdos, sentencias y precedentes judiciales han originado un inusitado debate público y académico de análisis y crítica, e incluso - por ejemplo- se han creado asignaturas y cursos especialmente para tratar los plenos casatorios, que trascienden las fronteras de las instituciones académicas de los órganos del sistema de justicia, como sucede con la enseñanza universitaria de posgrado.

Finalmente, el sustento democrático vertebrado también abarca las labores de gestión y la estructura orgánica y funcional de los órganos de gobierno del Poder Judicial peruano. Se tiene, por ejemplo, la participación de la comunidad jurídica en el Consejo Ejecutivo del Poder Judicial, como un rasgo relevante en estos años, producto del modelo participativo de reforma. En efecto, la participación en dicha instancia de gobierno de un representante externo al Poder Judicial elegido por los colegios de abogados del Perú, es una práctica interesante, de vital significado en la toma de decisiones y de imposición de medidas disciplinarias; y que se repite en los Consejos Ejecutivos distritales a nivel nacional. Por supuesto que habrá que perfeccionar aquello que se deba mejorar, por cuanto de lo que se trata es de no asumir una suerte de "presidencialismo judicial» desbordante o que paradójicamente se termine en un

9 Véase Herrendorf, Daniel E. (1994). El poder de los jueces. Cómo piensan los jueces que piensan. Buenos Aires: Abeledo-Perrot. 
«presidencialismo corporativo» que repose en un grupo de jueces afortunados; sino una visión corporativa y colegiada democrática y participativa de los órganos de gobierno judicial ${ }^{10}$. En ese sentido, el delicado papel de los magistrados, quienes deciden por aquello que es valioso para cada ser humano dentro de un proceso judicial, y el rol de los magistrados en labores de gestión institucional, merecen el control social y el control democrático de sus actos.

Sobre la referida práctica institucionalizada, debe precisarse que el equilibrio y control de poderes, más aún en un modelo horizontal como el nuestro, no debe admitir excepciones, pues ello puede originar desviaciones que pueden terminar ahogando la democracia. Si cada poder del Estado tiene precisamente una cuota de poder político y/o jurídico, entonces la democracia conlleva a ampliar y regular la participación ciudadana en todas las esferas de la cosa pública. En consecuencia, el modelo de participación y control de la sociedad en la organización estatal es un derecho constitucional democrático y contemporáneo que no solo debe ser de aplicación a la esfera judicial, sino también a todo el sistema de pluripoderes, como elemento catalizador del fenómeno democrático.

En mérito de lo hasta aquí expuesto, la calidad de una democracia, de una democracia inclusiva y participativa significa un Poder Judicial fuerte. Una organización judicial nacional sólida comprende, evidentemente, la plena función jurisdiccional y política del juez. La función política y social de la magistratura o la legitimidad democrática del juez (en su función legitimadora del Estado) es el tema de la hora presente, y eso es pensar en una justicia republicana. Así las cosas, una democracia sin justicia no es democracia (justicia en democracia).

10 Interesa al respecto EsPinosA-SALDAÑA BARrERA, Eloy (2003). «La impartición de justicia en la propuesta de reforma constitucional peruana recientemente debatida». Jurisdicción constitucional, impartición de justicia y debido proceso. Lima: ARA Editores, 375-408. 
Con estas credenciales, la reforma del Estado en general y la reforma del Poder Judicial en particular, aspectos que se tratarán en las líneas que siguen, tienen una mejor comprensión desde el pensamiento democrático judicial, el mismo que conlleva un sentido de pertenencia de la justicia, identificación con un sistema confiable de justicia y de empoderamiento del usuario de los servicios judiciales como líneas capitales para importantes y eficientes políticas públicas $^{11}$. Ayuda mucho, del cuadro anteriormente descrito, la necesidad de impulsar en la formación de los jueces y fiscales $-\mathrm{y}$ de la abogacía en general- la enseñanza de la democracia y la judicatura, la democracia constitucional y el quehacer jurisdiccional, el enfoque democrático-constitucional de las reformas judiciales. Es la Academia de la Magistratura, en principio, la encargada de asumir o reorientar este desafío (sin olvidar, por supuesto, la etapa universitaria, absolutamente fundamental para todo proceso de transformación a largo plazo) ${ }^{12}$.

\section{LA REFORMA DEL ESTADO Y LA JUDICATURA NACIONAL: ¿REFORMAR LA REFORMA?}

La reforma política y judicial del corriente año como efecto natural de la prolongada crisis política (inclúyase el conflicto entre poderes de origen popular) y producto de la enorme crisis que sacudió los cimientos del sistema de justicia y del aparato judicial, obliga a plantearse la necesidad de hacer cambios y transformaciones institucionales.

11 Léase, Rodríguez Albán, Miguel (2018). El Estado y las políticas públicas. Enfoque jurídico y político. Prólogo de Helder Domínguez Haro. Trujillo: Librorum.

12 Sobre este asunto en particular, a nivel universitario las cosas podrían ser mejor, en la maestría en Derecho con mención en Política Jurisdiccional de la Pontificia Universidad Católica del Perú, el curso de Reformas Judiciales en América Latina tiene el carácter electivo (no obligatorio), lo cual es una desventaja y un despropósito en la formación histórica y presente de los alumnos. Ello no sucede con otros dos cursos también importantes y esta vez obligatorios, me refiero a los cursos sobre Políticas Públicas y Jurisdicción y Sistemas Judiciales Comparados. 
En el caso de la judicatura peruana, si bien no se puede precisar históricamente cuándo se inició el proceso de reforma judicial, un punto de especial referencia será a inicios de la década seis del siglo pasado, aunque el problema judicial del siglo XX se remonta al Oncenio y continúa desde el año 1930, lo que hace pensar que la crisis del sistema judicial tiene su tiempo de marchas y contramarchas, de actos de resistencia o de militante colaboración con el poder político ${ }^{13}$, por cuanto se ha oscilado entre la democracia y el autoritarismo propio de la centuria pasada. Se afirmaba que el prestigio del Poder Judicial hasta 1920 era prácticamente indiscutible ${ }^{14}$, y como explicará Domingo García Belaúnde, la judicatura peruana en el siglo XIX hasta inicios del siglo XX funcionó bien, con altas y bajas, «en parte porque no habían surgido las dificultades que solo afloraron más tarde y que erosionaron el servicio de justicia. Esto no quiere decir que no haya habido críticas y propuestas, pero ellas en realidad eran escasas y estaban prácticamente circunscritas a determinadas épocas, áreas o situaciones» ${ }^{15}$.

Si bien los sucesivos gobiernos desde la década de los treinta del siglo XX, fueron en buena parte administradores de la crisis económica, lo cierto es que han existido diferentes modalidades y alternativas de reformas de la judicatura. Básicamente, la reforma de los sesenta (Comisión para la Reforma del Poder Judicial creada por la Ley n. ${ }^{\circ} 13036$ en noviembre del año 1958, y una avanzada Ley Orgánica del Poder Judicial, Decreto Ley n. ${ }^{\circ} 14605$ de 1963); la reforma militar de la década de los setenta (Comisión

13 Ramos Núñez, Carlos (2008). Historia de la Corte Suprema de Justicia del Perú. Lima: Fondo Editorial del Poder Judicial, 28.

14 SÁnchez, Luis Alberto (1988). El Perú: nuevo retrato de un país adolescente. Lima: Mosca Azul, 98.

15 García Belaúnde, Domingo (2004). El Poder Judicial en la encrucijada. Lima: Ara Editores, 69. 
de Reforma Judicial creada por Decreto Ley n. ${ }^{\circ} 21307$ de 1975, previa aparición del Consejo Nacional de Justicia a través del Decreto Ley n. ${ }^{\circ} 18060$ de 1969 y cuya consagración a escala constitucional como Consejo Nacional de la Magistratura se da con la Constitución de 1979); la llamada reforma y modernización de la justicia de los noventa (Comisión Ejecutiva del Poder Judicial originada por la Ley n. ${ }^{\circ} 26546$ de 1995; formación del Consejo de Coordinación Judicial mediante la Ley n. ${ }^{\circ} 26623$ de 1996; una nueva Ley Orgánica del Poder Judicial sancionada previamente por el Decreto Legislativo n. ${ }^{\circ} 767$ de 1991, modificada sustancialmente por el Decreto Ley n. ${ }^{\circ} 25869$ de 1992, que ocasionó un Texto Único Ordenado aprobado por el Decreto Supremo n. ${ }^{\circ} 017-93-J U S ;$ e igualmente la Ley Orgánica del Consejo Nacional de la Magistratura, Ley n. ${ }^{\circ} 26397$ acorde con la Constitución de 1993, la misma que mantiene la separación del Poder Judicial y del Ministerio Público, como sucedió con la Constitución de 197916); y la restructuración y refundación judicial a inicios del siglo XXI (corresponden al año 2003 la Comisión Especial para la Reforma Integral de la Administración de Justicia-Ceriajus creada por la Ley $n .^{\circ}$ 28083, y las originadas desde la judicatura nacional, Comisión de Magistrados para la Reestructuración Judicial y Acuerdo Nacional por la Justicia). Es cierto también que ante la nueva crisis de corrupción judicial desbordada en la mitad del año 2018 (de mayor intensidad que la producida en el 2005, se adoptaron en su tiempo medidas para la llamada reestructuración de la administración de justicia), se está produciendo un nuevo ciclo de reformas.

16 Domingo García Belaúnde ha advertido que la Constitución de 1993 se discutió y aprobó teniendo como plantilla la Carta Política de 1979, a la que repite en más del 65 \% de sus enunciados. Véase García Belaúnde, Domingo (1996). «La reforma del Estado en el Perú». En AA. VV. La reforma del Estado. Estudios comparados. México D. F.: UNAM/Dirección General de Asuntos Jurídicos de la Presidencia de la República, 389. 
Esta nueva época de tratamiento y solución a la crisis del sistema de justicia (una suerte de «cuarta» o «quinta oleada» de reformas, para aquellos que siguen la historia judicial o la «segunda» oleada del siglo XXI), ha sido temporalmente abordada, a modo de ilustración, en dos subetapas:

a) En la segunda mitad del 2018, por la Comisión Consultiva denominada Comisión de Reforma del Sistema de Justicia del Poder Ejecutivo (Resolución Suprema n. ${ }^{\circ}$ 142-2018PCM, de fecha 12 de julio), por la Sala Plena de la Corte Suprema de Justicia, a través del Plan de Cambios Urgentes del Poder Judicial y por las seis comisiones especializadas nacidas de la propia Corte Suprema de Justicia, como son las Comisiones de Integridad y Control Institucional, para la Reformulación de las Prácticas y Competencias Casatorias de la Corte Suprema, para la Reforma Estructural, Orgánica y Operativa del Consejo Nacional de la Magistratura y la Academia de la Magistratura, para la Adaptación Estratégica de los Procedimientos y Competencias en lo Contencioso Administrativo, para la Democratización y Transparencia de la Elección para Nuevas Autoridades Judiciales, y Comisión para la Modernización Tecnológica y de los Procesos de Optimización del Servicio Judicial (Acuerdo n. ${ }^{\circ}$ 32-2018, Décimo Segunda Sesión Extraordinaria de la Sala Plena de la Corte Suprema de Justicia). Comprende también la Ley n. ${ }^{\circ}$ 30833, que declara en situación de emergencia el Consejo Nacional de la Magistratura y suspende su Ley Orgánica (Diario Oficial El Peruano del 28 de julio de 2018).

b) En el 2019, el proceso de reforma ha tomado cuerpo y figura humana a través de una especie de comité de crisis al más alto nivel denominado Consejo para la Reforma del Sistema de Justicia creado por la Ley n. 30942 (Diario Oficial El Peruano del 8 de mayo) y conformado por los titulares de 
los poderes públicos representativos (presidente de la República, presidente del Congreso de la República, presidente del Poder Judicial, presidente del Tribunal Constitucional, fiscal de la nación, presidente de la Junta Nacional de Justicia, contralor general de la República y defensor del pueblo). En ese contexto descrito, a la pregunta quién nombra y quién controla, la respuesta ha sido la aprobación de una ley de reforma constitucional sobre un tema peliagudo y sensible como es la elección de los jueces y fiscales, y dos leyes que modifican de manera radical el Texto Único Ordenado de la Ley Orgánica del Poder Judicial, la Ley Orgánica del Ministerio Público y Ley de la Carrera Judicial sobre los órganos de control del aparato judicial y fiscal; con lo cual se tiene la siguiente plataforma normativa vigente: Ley $n .^{\circ} 30904$ sobre la conformación y funciones de la Junta Nacional de Justicia (Diario Oficial $E l$ Peruano del 10 de enero de 2019), Ley n. ${ }^{\circ}$ 30943, Ley de Creación de la Autoridad Nacional de Control del Poder Judicial y Ley n. ${ }^{\circ}$ 30944, Ley de Creación de la Autoridad Nacional de Control del Ministerio Público (Diario Oficial El Peruano del 8 de mayo de 2019 para ambas), las cuales ciertamente han generado comentarios y opiniones de diversa magnitud.

Ante este escenario constitucional y legal, de lucha contra la corrupción, contra la morosidad y el retardo, en la búsqueda de ir reduciendo y eliminando la impunidad, los factores de riesgo del fenómeno de la corrupción ${ }^{17}$, reforzada con la promoción de los valores éticos (tarea conjunta del Estado, la sociedad y la

17 Como síntesis de la problemática, en términos generales y preliminares sobre la justicia para el debate público, se puede citar el informe preparado por Gaceta Jurídica titulado: La justicia en el Perú. Cinco grandes problemas. Documento preliminar 2014-2015. Lima, 2015. 
familia ${ }^{18}$ y el uso de la tecnología, como el inicio del expediente electrónico en los órganos jurisdiccionales para transparentar y dar celeridad a los actos, las soluciones si bien deben darse de modo frontal, también deben siempre apuntar desde una perspectiva democrática sin viejos intervencionismos que puedan dañar una real autonomía e independencia del quehacer jurisdiccional en relación con el poder central y político.

Evidentemente, una reforma judicial «sin» los jueces o «solo» de jueces no funciona. Por ello, el Poder Judicial debe asumir el rol protagónico de liderar una reforma participativa y sistémica en aras de una justicia sólida y orgánica, sin duda, formando alianzas con los diferentes poderes y sectores de la sociedad, y con la participación de los organismos cooperantes internacionales (desde una perspectiva de la autonomía del sistema judicial y los derechos humanos). Vale decir, un cambio y reconfiguración desde el mismo Poder Judicial y no desde afuera. El jurista Domingo García Rada afirmaba que la reforma es provechosa cuando es auspiciada por el propio Poder Judicial ${ }^{19}$. En los últimos quince años, que comprenden la declaratoria de emergencia del Poder Judicial del año pasado, este poder del Estado ha presentado distintos proyectos de ley al Congreso de la República, en torno a mejorar la calidad del servicio de la justicia en el ámbito organizativo, funcional y jurisdiccional (inclúyase el acceso a la justicia y la diversidad cultural en la agenda del Poder Judicial). Sin embargo, no ha tenido la acogida esperada por el Parlamento

18 A nivel de las relaciones familiares, el artículo 463, inciso 1 del Código Civil prescribe que los padres pueden ser privados de la patria potestad cuando dan ejemplos corruptos a sus hijos.

19 Memoria del señor presidente de la Corte Suprema de Justicia de la República doctor don Domingo García Rada. Leída en la ceremonia de apertura del año judicial de 1969. En Anales Judiciales de la Corte Suprema de Justicia de la República. Años judiciales de 1967-1968-1959. Tomo LXII. Publicación oficial, 1971. Lima: Imprenta Minerva, 238. 
(ver en el anexo algunas propuestas); así como también han quedado al interior del Poder Judicial interesantes propuestas y reformas legales que seguramente verán la luz en algún momento del devenir republicano, como, por ejemplo, una nueva Ley Orgánica del Poder Judicial, proyectos para atacar la sobrecarga procesal y el retardo en la impartición de justicia, y sobre la designación judicial (selección, evaluación y ratificación de jueces) partiendo primero por la transformación de la Academia de la Magistratura en una Escuela Judicial con periodos académicos prolongados y obligatorios para acceder a la judicatura. No debe soslayarse ni perderse de vista, en todo proceso de reforma integral, la capacitación como política pública fundamental y dimensión relevante del sistema judicial; consiguientemente, se requiere profundizar y fortalecer la profesionalización de la educación judicial a través de una moderna Escuela Judicial ${ }^{20}$. De esta última visión característica de la propuesta del Poder Judicial, y en ese orden, carecían los diferentes proyectos que modificaban el desaparecido Consejo Nacional de la Magistratura, y a su turno, finalmente, la ley de reforma constitucional creadora de la Junta Nacional de Justicia.

Y si de capacitación judicial se trata, se debe poner las cosas en su justo lugar para que se tenga una sustancial reforma, circunscribiendo la enseñanza legal-judicial en cinco grandes bloques: derecho constitucional, derechos humanos, ética judicial, argumentación jurídica y derecho judicial; que deben abordarse transversalmente desde la democracia constitucional y la filosofía del derecho.

Si bien es una ardua tarea renovar el sistema de justicia, por cuanto existe el enemigo de la corrupción, hoy por hoy urge una

20 Desde 1996 al 2019, es decir, desde la creación de la Comisión de Reorganización y Gobierno de la Academia de la Magistratura hasta la fecha, han pasado aproximadamente veinte directores generales en veintitrés años, lo que nos obliga a replantear el estado de cosas existente. 
reingeniería de la justicia (reingeniería humana), en la búsqueda de un mayor rendimiento de los agentes involucrados, en función de una plataforma de ideas, valores y principios constitucionales con espíritu de permanencia, sintonizados en políticas democráticas sobre la administración e impartición de justicia, en la trilogía eficiencia-justicia-ética en beneficio del ciudadano, y que deben responder a la interrogante ¿qué Poder Judicial necesita el país?, o utilizando expresiones del maestro Fix Zamudio, la reforma judicial ¿de dónde viene?, y ¿hacia dónde va? ${ }^{21}$. En este recorrido, es absolutamente vital en la conducción del Poder Judicial, adelante y atrás en el proceso de reforma, la acción propositiva (y no conservadora) y de autocrítica de los jueces supremos y su nivel de compromiso con la gobernabilidad judicial.

Partamos de la persona y hacia la persona. El mejoramiento del sistema de justicia es también una cuestión de personas, de conciencias, que por su complejidad es una permanente lucha por generar prototipos de magistrados mayoritariamente probos y de pensamiento crítico a tono con la realidad, en aras de la vigencia social de la judicatura. Un diseño institucional con una cultura judicial de tales características asegura importantes reformas democráticas.

De lo hasta aquí desarrollado, para su concreción se requiere en gran medida de la voluntad política de cambio o de la famosa «intencionalidad política» por parte no solamente de la Presidencia del Poder Judicial, la Sala Plena y el Consejo Ejecutivo, involucra -inexcusablemente - el compromiso institucional y económico de los poderes Ejecutivo y Legislativo. A nivel institucional, la reforma constitucional y legal del servicio de justicia es una oportunidad de prueba de dicho compromiso; y a nivel económico y presupuestario, si bien el dinero no lo es todo en la vida, nadie puede negar que es

21 Léase Fix Zamudio, Héctor (2002). La reforma judicial en México. ¿De dónde viene? ¿Hacia dónde va? México: UNAM-Instituto de Investigaciones Jurídicas. 
necesario para alcanzar los logros que la sociedad espera; y si bien el tener los recursos económicos suficientes tampoco asegura la solución de los problemas en torno a la judicatura, su eficiente uso y redistribución desde un enfoque sistémico y políticas democráticas equitativas, es un buen parámetro para una reforma de corto plazo y de largo aliento. Si el Estado asignara los montos presupuestarios suficientes y coherentes con la implementación de la reforma procesal penal y la reforma procesal laboral, no se estaría todavía en plena implementación (en el primer caso van trece años; $y$, en el segundo, nueve años). No menos importante es el impacto de las remuneraciones de los diferentes actores en todo proceso de reforma, especialmente la necesidad de una retribución competitiva para los trabajadores jurisdiccionales y administrativos. En definitiva, invertir en justicia significa dotar de una real autonomía presupuestal a la judicatura.

La reestructuración judicial democrática del siglo XXI no comprende ni se agota en el periodo de un determinado presidente de la República y de un presidente del Poder Judicial, es todo un proceso continuo de políticas públicas en lo organizacional y jurisdiccional preestablecidas, un devenir, haciéndose permanentemente por las exigencias sociales en el camino de una justicia independiente, predecible y moderna (el servicio de justicia no al servicio del poder), y desde esa perspectiva habrá que juzgarla.

\section{APUNTES BIBLIOGRÁFICOS: REACTUALIZAR LA JUSTICIA}

Sobre el sistema de justicia y particularmente del Poder Judicial peruano se tiene una copiosa literatura, y no obstante dicha dificultad, con el presente trabajo intentamos aproximarnos o acercarnos al proceso de reforma judicial desde los diferentes libros -individuales y colectivos-, publicaciones, folletos y documentos de trabajo en sede nacional. Un primer intento de esquema bibliográfico que de hecho no es completo por diferentes razones 
y variables; pero trata de reunir lo esencial sobre tan palpitante tema como es la reforma, modernización, reestructuración y refundación de la judicatura, para que de ese modo no se pierda el rumbo al no tenerse fuentes bibliográficas mínimas.

Se han considerado publicaciones del siglo XX y como fecha de cierre hasta el año 2011 (las que aparecen sin fechas se ha creído pertinente incluirlas en la lista porque su revisión atañe al periodo estudiado), correspondiente a la primera década, por cuanto está en preparación una segunda entrega actualizada. Por ahora no se han considerado probablemente algunos aspectos sectoriales, de especialidad o nuevos temas dentro del estudio del derecho judicial, jurisdiccional y de la justicia en general; ni artículos en revistas o publicaciones periódicas que existen -en buen número y por temas de especialidad-, porque el tiempo ha sido mi permanente enemigo. Sin embargo, se pueden revisar, a guisa de ejemplo: los Anales Judiciales de la Corte Suprema de Justicia, la Revista Oficial del Poder Judicial y de la Corte Suprema de Justicia, y la Revista de la Academia de la Magistratura. En igual sentido, es ilustrativa la lectura de los diferentes informes de la Comisión Interamericana de Derechos Humanos en lo que concierne al tema desarrollado, de la Organización de Estados Americanos cuando aborda aspectos de la administración de justicia y de la Relatoría Especial de las Naciones Unidas sobre independencia de magistrados y abogados.

Finalmente, se ha agregado bibliografía básica comparada correspondiente a nuestro continente, bibliografía complementaria a la reforma judicial y, además, a nivel constitucional e histórico de hechura nacional.

\subsection{Bibliografía sobre reforma judicial}

AlCAbÉs, Nissim (1999). Aportes a una nueva Ley Orgánica del Poder Judicial: la carrera judicial, evaluación del desempeño 
de los magistrados judiciales, estructura y gobierno del Poder Judicial. Lima: New Graf.

Alegría Campos, Mario (1972). Poder Judicial: reforma urgente. Lima: Chiabra.

Alonso, Pablo (2003). «Programa de acceso de mejoramiento a la justicia en el Perú». VIII Congreso Internacional del CLAD sobre la Reforma del Estado y de la Administración Pública. Panamá: CLAD, 1-12.

Álvarez Dueñas, Pedro (2009). Notificación electrónica en el Poder Judicial. Arequipa: Adrus.

Alzamora Valdez, Mario (1963). La nueva Ley Orgánica del Poder Judicial. Lima.

Amoretti Pachas, Mario (2009). ¿Reforma judicial? Lima: Magna. AnChorena, Carlos (1939). Por la pronta y buena administración de justicia. Lima: Atlántida.

Arias Lazarte, Carlos y Bolívar, Adelaida (1996). La casación civil en cifras. Lima: Cultural Cuzco.

Avendaño, Jorge (2000). «Sobre reforma judicial». A la luz del derecho. Cinco años en el Congreso de la República. Trujillo: Normas Legales.

BARros, Óscar C. (1940). Por la justicia y porla patria: «Devolveremos al Poder Judicial su excelsitud». Lima: Taller de Linotipia.

(1941). El atropello contra la Corte Suprema en 1930 y su inminente solución por el Congreso de 1941. Lima: Taller de Linotipia.

(1942). ¿En dónde está la justicia? ¿En dónde está la verdad? Lima: Taller de Linotipia.

Belaúnde, Víctor Andrés (1987). «El Poder Judicial». El debate constitucional. Tomo IV. Lima: Comisión Nacional del Centenario de Víctor Andrés Belaúnde. 
(1998). «Democracia y Poder Judicial». En Planas Silva, Pedro. Democracia y tradición constitucional en el Perú: materiales para una historia del derecho constitucional en el Perú. Lima: San Marcos.

Binder, Alberto, Burgos Mariños, Víctor, Schönbohm, Horst, Mixán Máss, Florencio, Castañeda Díaz, Julio César, Valencia Llerena, Niccy Mariel y Chang Chang, Silvia (2009). La realidad de la reforma procesal penal en el Perú. Trujillo: Ediciones BLG.

Burgos Mariños, Víctor (2008). El Proyecto Huanchaco y su aporte a la reforma del proceso penal en el Perú. Trujillo.

Bustamante Cisneros, Ricardo (1949). La reforma procesal. Lima: Editorial Peruana.

Bustamante y Rivero, José Luis (1963). «El Proyecto de Reforma del Poder Judicial». En Pareja Paz Soldán, José (dir.). Visión del Perú en el siglo XX. Tomo II. Lima: Librería Studium.

Bustamante Zegarra, Ramiro Antonio (2008). «Reforma del Poder Judicial». En AA. VV. Ponencias desarrolladas en el IX Congreso Nacional de Derecho Constitucional. Tomo I. Arequipa: Adrus.

Calderón Puertas, Carlos y Alfaro, Rosario (2001). La casación civil en el Perú. Trujillo: Normas Legales.

Cárdenas Muñoz, Roberto (1976). Esquema de un nuevo sistema judicial para el Perú: con organigrama del actual sistema y del propuesto. Lima: Noriega.

Castañeda Otsu, Susana Ynés (2003). «El Poder Judicial de Perú y el proceso de reforma constitucional». En García Belaúnde, Domingo (coord.). La Constitución y su defensa: algunos problemas contemporáneos. Instituto Iberoamericano de Derecho Constitucional (Sección peruana). Lima: Grijley. 
(2011). «El procedimiento de destitución de jueces en Perú y jurisprudencia del Tribunal Constitucional». En ETo Cruz, Gerardo (coord.). Horizontes contemporáneos del derecho procesal constitucional: liber amicorum Néstor Pedro Sagüés. Tomo II. Lima: Centro de Estudios Constitucionales/Editorial Adrus.

Castro Gargurevich, Martín (2002). Reforma judicial en el Perú en el contexto de la transición democrática. II Foro Temático Regional Gobernabilidad para el Empoderamiento de los Pobres. Lima: Banco Mundial.

Castro Stagnaro, Raúl (2008). «El proceso de reforma de la administración de justicia en el Perú. Comprendiendo la reforma para comprender y seguir avanzando». En CASTILlo Freyre, Mario (coord.). Libro homenaje a Felipe Osterling Parodi. Volumen II. Lima: Palestra Editores.

Catacora, Manuel, De Belaunde, Javier, Linares Alencastre, Octavio y Manchego Adrián, Hugo (1988). Nueva estructura del Poder Judicial. Proyecto de Ley Orgánica del Poder Judicial. Lima: Edimssa.

Chiara Galván, Eduardo Rolando (2010). «Las notificaciones electrónicas en la administración de justicia del Perú». IV Congreso Nacional de Magistrados del Poder Judicial. Documentos de trabajo. Lima.

Cornejo, Mariano H. (1916). La reforma del procedimiento penal en el Perú: en pro y en contra del jurado. Lima: Imprenta del Estado.

Corrales Melgarejo, Ricardo (2011). Reflexiones sobre el buen juez. Huancayo.

Cuentas Olaechea, Enrique A. (1998). Por los caminos de la justicia. Proceso a la Corte Suprema. Lima: s. e. 
Dargent Bocanegra, Eduardo (2006). «Reforma judicial en el Perú (1990-2005)». En Crabtree, John (ed.). Construir instituciones: democracia, desarrollo y desigualdad en el Perú desde 1980. Lima: Fondo Editorial de la Pontificia Universidad Católica del Perú/Centro de Investigación de la Universidad del Pacífico/Instituto de Estudios Peruanos.

DAvis, William (1996). Informe al Programa de las Naciones Unidas para el Desarrollo (PNUD) sobre el proceso para la reforma del sistema de justicia en el Perú. DPK Consulting. San Francisco: PNUD.

De Belaunde López de Romaña, Javier (1985). «La administración de justicia». En AA.VV. Problemas de urgencia en el Perú. Lima: Centro Peruano de Investigación Aplicada.

(1999). «La independencia judicial y las incoherencias de la reforma judicial». En AA. VV. Reforma constitucional. Primer Congreso de Reforma Constitucional. Fundación Friedrich Ebert (FES). Arequipa: Edigraf.

(2000). «Justicia, legalidad y reforma judicial en el Perú (19901997)». En Crabtree, John y Thomas, Jim (eds.). El Perú de Fujimori 1990-1998. Lima: Universidad del Pacífico/Instituto de Estudios Peruanos.

(2005a). "Algunas propuestas para la reforma del sistema judicial peruano». Cuadernos de Formación n. ${ }^{\circ}$ 2. Lima: Instituto de Estudios Social-Cristiano/Fundación Konrad Adenauer.

(2005b). «Diez temas fundamentales sobre la administración de justicia». Reforma del Estado. Reforma de la Constitución. Lima: CAJ/Fundación Konrad Adenauer.

(2006). La reforma del sistema de justicia. ¿En el camino correcto? Breve balance de su situación actual y de los retos pendientes. Lima: Konrad Adenauer Stiftung/Instituto Peruano de Economía Social de Mercado. 
(2007). «El papel de la justicia». En Tovar, Cecilia (ed.). La reconciliación en el Perú: condiciones y desafíos. Lima: Centro de Estudios y Publicaciones e Instituto Bartolomé de las Casas. (2008). «El Poder Judicial: la reforma siempre pendiente». En PÁsara, Luis (ed.). Perú hoy siglo XXI. Lima: Fondo Editorial de la Pontificia Universidad Católica del Perú. (2011). «La justicia: ¿hay esperanza?». En PÁsAra, Luis (ed.). Perú ante los desafíos del siglo XXI. Lima: Fondo Editorial de la Pontificia Universidad Católica del Perú.

De Trazegnies Granda, Fernando (1992). «Poder Judicial base de la democracia». Paz y bienestar social: asumamos responsabilidades. Conferencia Anual de Ejecutivos (CADE) 92. Lima: Instituto Peruano de Administración de Empresas (IPAE).

(1994a). "Administración de justicia y resolución de conflictos». Empleo productivo: responsabilidad de todos. Conferencia Anual de Ejecutivos (CADE) 94. Lima: Instituto Peruano de Administración de Empresas (IPAE).

(1994b). «El sistema judicial peruano». En BozA, Beatriz (ed.). Invirtiendo en el Perú: guía legal de negocios. Lima: Apoyo. (1996). Reflexiones sobre la sociedad civil y el Poder Judicial. Lima: Ara Editores.

Domínguez Haro, Helder (2009). Lectura bibliográfica sobre la democracia y la judicatura nacional como poder del Estado. Lima.

Du Bois, Eduardo (1925). El Tribunal Supremo. Lima.

Durán AbARCA, Washington (1971). Bases para la reforma de la función judicial. Lima: Pérez Pacussich.

Echecopar, Enrique (1927). Justicia inmediata. Hagamos que los jueces fallen las controversias en el mismo tiempo que los juristas absuelven consultas sobre controversias. Lima. 
(s. f.). Reformas judiciales. Lima.

Echevarría Adriazén, Andrés (2008). «La reforma del Poder Judicial en la Oficina de Control de la Magistratura». En Castillo Freyre, Mario (coord.). Libro homenaje a Felipe Osterling Parodi. Volumen II. Lima: Palestra Editores.

Eguiguren Praeli, Francisco José (1999). ¿Qué hacer con el sistema judicial? Lima: Agenda Perú.

(2002). «El Consejo Nacional de la Magistratura». Estudios Constitucionales. Lima: ARA Editores.

Eguiguren Praeli, Francisco José (coord.) (2002). Propuestas para la reforma de la Ley Orgánica del Poder Judicial: gobierno y administración del Poder Judicial, organización de la función jurisdiccional y sistema de carrera judicial. Lima: Pontificia Universidad Católica del Perú y Agencia de los Estados Unidos para el Desarrollo Internacional (USAID).

Elguera Valega, Luis (s. f.). El Poder Judicial en la historia del Perú. La Corte Suprema en las dictaduras del siglo XX. Lima.

Elías Jiménez, Enrique (2004). Justicia: cuestión de Estado y sociedad. Chiclayo: JASV Producciones Especiales.

EsPinosA-SALDAÑA BARRERA, Eloy (2003). Jurisdicción constitucional, impartición de justicia y debido proceso. Lima: ARA Editores.

(2005). «Sobre la constitucionalización de elementos de la carrera judicial: qué incluir y bajo qué consideraciones». En AA. VV. Ponencias desarrolladas en el VIII Congreso Nacional de Derecho Constitucional. Lima: Fondo Editorial del Colegio de Abogados de Arequipa.

(2008a). «Impartición de justicia en el Perú: algunos comentarios sobre la propuesta de reformas constitucionales hoy en trámite». En AA.VV. Ponencias desarrolladas en el IX Congreso Nacional de Derecho Constitucional. Tomo I. Arequipa: Adrus. 
(2008b). «Evaluación del desempeño de los jueces: ideas sobre las técnicas a aplicar y el organismo responsable a materializarla». En EsPinosa-SALdAÑa Barrera, Eloy y Gutierrez Ticse, Gustavo (dirs.). Limitación del poder y estructura del Estado. Estudios sobre la parte orgánica de la Constitución. Lima: Grijley.

Eтo Cruz, Gerardo (2011). «El juez: el señor juez del derecho». En AA. VV. Memoria del X Congreso Nacional de Derecho Constitucional y III Congreso Nacional de Derecho Procesal Constitucional Néstor Pedro Sagüés. Asociación Peruana de Derecho Constitucional, Universidad Peruana de Los Andes. Huancayo: Agencia de Publicidad Creative.

Febres, Leonidas (1969). Memorias de un juez. Lima: Editorial Gráfica Stylo.

Ferrero Costa, Raúl (1999). "Crisis del sistema de justicia». Trabajos de derecho constitucional. La constitución mediatizada. Lima: Grijley.

(2002). «La administración de justicia en el Proyecto de Bases de la Reforma Constitucional». La transición en marcha. Lima: Grijley.

(2006). «Reforma del Poder Judicial». La reforma constitucional pendiente y otros escritos. Lima: Nomos \& Thesis.

(2008a). «Reforma del Poder Judicial y otros temas jurídicos».

La reforma del Estado y la reforma constitucional pendiente. Lima: Grijley.

(2008b). «La reforma judicial y sus repercusiones». En Castillo Freyre, Mario (coord.). Libro homenaje a Felipe Osterling Parodi. Volumen II. Lima: Palestra Editores.

Figueroa Navarro, Aldo (2005). «Desafíos y perspectivas en la implementación del nuevo despacho judicial en Lima metropolitana». Lima. 
Flores-Aráoz Esparza, Ántero (2005). "Aún no hay reforma judicial». Autoritarismo o democracia (1990-2000). Biblioteca del Congreso del Perú. Lima: Editorial Minerva.

García Belaúnde, Domingo (1993). «Participación popular en la administración de justicia». En García Belaúnde, Domingo y Planas, Pedro. La constitución traicionada. Páginas de historia reciente. Lima: Seglusa Editores.

(1996). «La nueva Constitución del Perú: Poder Judicial y garantías constitucionales». En LANDA Arroyo, César, García Belaunde, Domingo y Zolezzi Ibárcena, Lorenzo. Desafíos constitucionales contemporáneos. Lima: Fondo Editorial de la Pontificia Universidad Católica del Perú.

(2004). El Poder Judicial en la encrucijada. Lima: ARA Editores.

García Calderón, Manuel (1973). Algunos hechos y reflexiones sobre la historia de la Corte Suprema de Justicia de la República. Lima: Universidad Nacional Mayor de San Marcos.

García Rada, Domingo (1944). Poder Judicial. Lima: Editorial Atlántida.

(1963). «El Poder Judicial en el siglo XX». En Pareja Paz Soldán, José (dir.). Visión del Perú en el siglo XX. Tomo II. Lima: Librería Studium.

(1978). Memorias de un juez. Lima: Editorial Andina.

García Salazar, José Antonio Bernard (1976). La justicia y sus problemas. Lima: Ebrasa.

(1983). En la carrera judicial: juez en provincias, en la Corte Suprema, en el Consejo Nacional de Justicia, ejemplos, anécdotas, comentarios. Lima: Sesator.

Garmendia, Roberto F. (1969). Reforma en el Poder Judicial. Lima: Imprenta Carrera.

Gómez Mendoza, Gonzalo (1993). Conflictos en la justicia de paz: necesidad y tratamiento en el campo penal. Lima: Rodhas. 
Gómez Valverde, Jaime y Camacho Miranda, Indira (2010). Propuesta de mejora del sistema de información de expedientes judiciales. Lima: Jurista Editores.

GonzÁlez D’Angelo, Vicente (2004). La justicia peruana: ensayo sobre la reforma del Poder Judicial. Lima: Cultural Cuzco.

Gonzáles Mantilla, Gorki (1998). Poder Judicial, interés público $y$ derechos fundamentales en el Perú. Lima: Fondo Editorial de la Pontificia Universidad Católica del Perú/Universidad Diego Portales de Chile.

(2008). «La enseñanza del derecho, cultura legal y reforma judicial». En Pease García, Henry y Peirano Torriani, Giofianni (eds.). Reforma del Estado peruano. Lima: Fondo Editorial de la Pontificia Universidad Católica del Perú. (2009). Los jueces: carrera judicial y cultura jurídica. Lima: Palestra Editores.

Gonzáles Polar, Rómulo Hugo (1992). Hacia una escuela de jueces. Arequipa: Universidad Nacional de San Agustín.

González Prada, Manuel (1972). «Nuestros magistrados». Horas de lucha. Lima: Universo.

Guerra Cerrón, María Elena (2004). Visión del sistema de justicia. Lima: Rodhas.

(2005). Hacia una justicia de paz: un asunto de interés nacional. Lima: Grijley.

Gutiérrez Ferreira, Carlos V. (1999). La formación psicológica de los magistrados. Lima: Cecosami.

Gutiérrez Ticse, Gustavo (2010). «El Consejo Nacional de la Magistratura en el Perú». Congreso Internacional sobre el Constitucionalismo en América Latina, 2 al 4 de febrero, Puebla, México.

Haro Bustamante, Róger L. (2009). Conceptos asociados a la gestión pública en las sentencias de la Corte Suprema de Justicia 
en materia de delitos cometidos por funcionarios públicos. Lima: Presidencia del Consejo de Ministros.

Herrera Paulsen, Darío (1963). «El Poder Judicial y la autenticidad del texto de las leyes». En Pareja Paz-Soldán, José (dir.). Biblioteca de cultura peruana contemporánea: derecho. Tomo 2. Lima: Ediciones del Sol.

(1978). Memoria del doctor Darío Herrera Paulsen, presidente del Consejo Nacional de Justicia. Lima: Editora Perú.

Hurtado Pozo, José (2009). Reflexiones sobre la reforma del Código Penal. Lima.

Israel Olivera, Raúl e Israel Olivera, Manuel J. (1985). Corrupción en el Poder Judicial y el Ministerio Público. Lima: San Marcos.

JimÉnez Mayor, Juan (2008a). «Reforma en la organización y gestión judicial: un reto pendiente». En Pease García, Henry y Peirano Torriani, Giofianni (eds.). Reforma del Estado peruano. Lima: Fondo Editorial de la Pontificia Universidad Católica del Perú.

(2008b). Nuevo diseño del régimen de estudios para la Academia de la Magistratura del Perú. Lima.

Lama More, Héctor (2007). «Perfil del juez». I Congreso Nacional de Magistrados del Poder Judicial. Documentos de trabajo. Lima.

Landa Arroyo, César (2003a). «Balance de la reforma judicial en el Perú, a la luz de los derechos fundamentales». En BAzÁn, Víctor (coord.). Defensa de la Constitución. Libro homenaje a Germán Bidart Campos. Buenos Aires: Ediar.

(2003b). «Tribunal Constitucional y Poder Judicial». Tribunal Constitucional y Estado democrático. Lima: Palestra Editores.

Ledesma Narváez, Marianella (1999). Jueces y reforma judicial. Lima: Gaceta Jurídica. 
(2002). La justicia de paz en Lima. Lima: Fondo Editorial de la Universidad Inca Garcilaso de la Vega.

León, José Matías (1936). 1930. La disolución del Poder Judicial. Lima: Sanmartí y Cía.

LEÓN y LEÓn, Bernardino (1916). Monografía sobre las reformas necesarias respecto de nombramientos y ascensos de los magistrados. Lima: Casanova.

(1925). El Poder Judicial. Somero examen de algunos de sus más graves y fundamentales problemas. Lima: Ed. Científica.

Linares Alencastre, Octavio (1972). La crisis judicial. Lima: Industrial Gráfica.

(1979). Órgano jurisdiccional y defensa judicial del Estado: para la Constituyente de 1978. Lima: Edimssa.

(1988). Organización del Poder Judicial. Lima: Edimssa.

(1989). Poder Judicial: crisis y emergencia. Lima: Edimssa.

(2001). Emancipación jurisdiccional. Lima: Jhire Grafel. (2003). El Poder Judicial en el proyecto constitucional. Lima.

Llerena Quevedo, Rogelio (1997). Código de ética judicial. Proyecto. Lima: Pontificia Universidad Católica del Perú Facultad de Derecho/Poder Judicial.

López Albújar, Enrique (1963). «Cómo entré en la carrera judicial y cómo me mantuve en ella». Memorias. Lima: Talleres Gráficos P. L. Villanueva.

MacLean Ugarteche, Roberto G. (1996). Lo que se espera de jueces y magistrados. Justicia. Guatemala.

(1997). «Réquiem para el espíritu del legislador: la cultura de servicio en la administración de justicia». En UNIVERSIDAD Nacional Autónoma de México. El papel del derecho internacional en América. La soberanía nacional en la era de la integración regional. México: UNAM-Instituto de Investigaciones Jurídicas, 330-360. 
(s. f.). La función social del juez: la cultura de servicio en la administración de justicia. Lima.

Malpartida Castillo, Víctor (comp.) (2007). Magistratura: un poder sin poder, encrucijada y diligencia. Lima: San Marcos.

Manchego Adrián, Hugo (dir.) (1989). Problemas de la justicia agraria en el Perú. Lima: Cultural Cuzco.

Manrique Zegarra, César Edmundo (2000). Autonomía, independencia y responsabilidad judicial: derecho judicial, derecho consuetudinario, epistemología jurídica. Lima: Instituto de Investigaciones Jurídicas y Judiciales.

MejíA, Beatriz (2000). «Informe de Perú». En Thompson, José (coord.). Acceso a la justicia y equidad: estudio en siete países de América Latina. San José: BID/IIDH, 249-326.

Mestanza, Oscar (2003). La reforma del Poder Judicial. Lima.

Miranda Canales, Manuel (2004). Sistema de nombramiento de magistrados en el Perú. Lima: Ediciones Jurídicas.

Mixán Máss, Florencio, Burgos Mariños, Víctor y Pérez Galimberti, Alfredo (2003). Proyecto Huanchaco. Código Procesal Penal peruano. Trujillo: Centro de Estudios para la Reforma de la Justicia Democracia y Libertad (CERJUDEL), Instituto de Estudios Comparados en Ciencias Penales y Sociales (INECIP) y Comisión Episcopal de Acción Social (CEAS).

Monroy Gálvez, Juan (1990). El Poder Judicial a 10 años de vigencia de la Constitución de 1979. Lima.

(2000). «El derecho y el ciudadano. La reforma del servicio de justicia». Para «mi otro corazón». Sobre derecho, proceso y otras angustias. Lima: Palestra Editores.

(2004). La función del juez en el derecho contemporáneo. Lima: San Marcos. 
Montoya Anguerry, Carlos (2009). «Ética judicial. Experiencia a nivel de Corte Superior». En AA. VV. Constitución y proceso. Libro homenaje a Juan Vergara Gotelli. Lima: Tribunal Constitucional y Jurista Editores.

Mosquera VÁsquez, Clara (2005). Ser juez en el Perú. Lima: Servicios Gráficos Sunset Color.

O’phelan Pérez, Fernando (2010). La justicia del diablo: bitácora de un viaje personal por la reforma judicial peruana $y$ latinoamericana. Lima: Projusticia.

Ortecho Villena, Víctor Julio (2010). «Gobernabilidad y sistema de administración de justicia». Estado y ejercicio constitucional. Trujillo: Marsol.

Parodi Remón, Carlos Augusto (1993). «La administración de justicia en el Perú». En Ovalle Favela, José (coord.). Administración de justicia en Iberoamérica. México: UNAMInstituto de Investigaciones Jurídicas.

PÁsARA, Luis (1978). Reforma agraria: derecho y conflicto. Lima: Instituto de Estudios Peruanos.

(1979). ¿Pueden cambiar los jueces? Trabajo presentado a la reunión sobre Derecho y Sociedad organizado por CLACSO. Buenos Aires.

(2010). Tres claves de la justicia en el Perú: jueces, justicia y poder en el Perú, la enseñanza del derecho, los abogados en la administración de justicia. Lima: Fondo Editorial de la Pontificia Universidad Católica del Perú.

PaZ-Soldán, Luis Felipe (1925). La administración de justicia en el Perú. Lima: Víctor Larco Herrera.

Peña Jumpa, Antonio (1998). Justicia comunal en los Andes del Perú, el caso de Calahuyo. Lima: Pontificia Universidad Católica del Perú. 
(2004). Poder judicial comunal aymara en el sur andino. Bogotá: ILSA.

(2009). Multiculturalidad y Constitución: el caso de la justicia comunal aguaruna en el Alto Marañón. Lima: Centro de Estudios Constitucionales del Tribunal Constitucional.

Pérez Del Valle, Carlos (2005). Estudios sobre la independencia judicial y el proceso penal. Lima: Grijley.

Planas, Pedro (1992). «Independencia judicial». Rescate de la Constitución. Lima: Abril Editores \& Impresores.

(1999). «Proceso a la reforma judicial (1992-1998)». El fujimorato: estudio político-constitucional. Lima: Talleres Gráficos Kelly.

Prado Saldarriaga, Víctor Roberto (2009). Nuevo proceso penal. Reforma y política criminal. Lima: IDEMSA.

Puentes del Barrio, Luis (1997). Juzgados de paz en la costa norte del Perú. Piura: Diaconía para la Justicia y la Paz.

RAMírez, Ramón (1985). Justicia y política. Lima: Empresa Editora Latina.

RAMírez Jiménez, Nelson (2001). La administración de justicia en el Perú. Luces y sombras. Lima.

Revilla, Ana Teresa y Price, Jorge (1992). La administración de la justicia informal: posibilidades de integración. Lima: Fundación M. J. Bustamante de la Fuente.

Rivera Paz, Carlos (1997). La reforma del Poder Judicial en el Perú. Lima.

Salas Arenas, Jorge (2010). La transacción: una justa solución al conflicto. Arequipa: Grupo Editorial Cromeo.

Salas Villalobos, Sergio (2002). Administración de justicia sostenimiento permanente para la reforma. Lima: Fondo Editorial de la Universidad Alas Peruanas. 
(2006). Cuadernos de derecho judicial. Lima: Projusticia.

San Martín Castro, César (2000). «Perú». En Maier, Julio B. J., Амвоs, Kai y Woischnik, Jan (coords.). Las reformas procesales penales en América Latina. Buenos Aires: Ad-Hoc, 657-718.

(2008). «La reforma procesal penal peruana: evolución y perspectivas». Taller descentralizado. Hacia el nuevo sistema acusatorio adversativo. Rumbo a la aplicación del nuevo Código Procesal Penal. Lima: Centro de Investigaciones Judiciales/ Proyecto de Apoyo a la Reforma del Sistema de Justicia del Perú, Jusper. Comunidad Europea, 172-217.

(2009). «Recurso de casación y Corte Suprema de Justicia: evaluación tres años después». La reforma del derecho penal y del derecho procesal penal en el Perú. Anuario de Derecho Penal, 209-219.

SÁnCHez, Luis Alberto (1988). «Los jueces». El Perú: nuevo retrato de un país adolescente. Lima: Mosca Azul Editores.

SEQueIros VArgas, Iván (2009). «La función judicial como parte de la estructura del poder del Estado». En AA. VV. Constitución y proceso. Libro homenaje a Juan Vergara Gotelli. Lima: Tribunal Constitucional y Jurista Editores.

TÁvara Córdova, Francisco A. (2007). Comentarios sobre el Consejo Nacional de la Magistratura. Lima: Gaceta Jurídica. (2008). «Exposición del Presidente de la Corte Suprema de Justicia y Presidente del Poder Judicial». En Pease García, Henry y Peirano Torriani, Giofianni (eds.). Reforma del Estado peruano. Lima: Fondo Editorial de la Pontificia Universidad Católica del Perú.

(2009). «La función del juez en un Estado constitucional de derecho. Ideas básicas». En AA. VV. Constitución y proceso. Libro homenaje a Juan Vergara Gotelli. Lima: Tribunal Constitucional y Jurista Editores. 
Tello Gilardi, Janet (2005). «Introducción al IV Seminario Internacional Independencia Judicial y Derechos Humanos». En Ciurlizza, Javier et al. Construyendo justicia: verdad, reconciliación y procesamiento de violaciones de derechos humanos. Lima: Fondo Editorial de la Pontificia Universidad Católica del Perú.

Torres, Ayax (1974). Las injusticias en la justicia peruana. Lima: Ediciones Jurídicas.

Torres y Torres Lara, Carlos (2003). «Poder Judicial más humanizado». Testimonio constitucional: colección homenaje. Lima: Asesorandina.

Valdivia Pezo, Ernesto (1996). Reformas en el Poder Judicial. Lima.

Villarán, Manuel Vicente (1962). Páginas escogidas. Lima: Talleres Gráficos P. L. Villanueva.

(1963). «El Poder Judicial». En Pareja Paz-Soldán, José (dir.). Biblioteca de cultura peruana contemporánea: derecho. Tomo 3. Lima: Ediciones del Sol.

Vinatea Medina, Ricardo (2009). La organización del despacho judicial y fiscal en el nuevo Código Procesal Penal. Lima: Gráfica Espinal.

Vega Billán, Rodolfo (2003). Enrique López Albujar: juez reformador del derecho penal. Huánuco: Universidad Nacional Hermilio Valdizán.

Vergara Gotelli, Juan Francisco (2004). La reforma del Poder Judicial (comprobaciones, reflexiones y propuestas). Lima: Kinkos Impresores.

YéPEz SÁnChez, Miguel (2000). Ética judicial. Lima. 


\section{ACADEMIA DE LA MAGISTRATURA (AMAG)}

Academia de la Magistratura (AMAG) (1996). Proyecto Formación y capacitación del Poder Judicial en Perú. Lima: AMAG/Unión Europea/Agencia Española de Cooperación Internacional (AECI).

(1997). Memoria 1996 y sintesis del Plan de Acción 1997. Lima: AMAG.

(1999). Contexto socioeconómico de la magistratura. Lima: AMAG.

(2000). Ética y revalorización del juez y el fiscal. Lima: AMAG. (2002). Fundamentos para una ética judicial. Lima: AMAG. (2003). Virtudes y principios del magistrado. Lima: AMAG. (2006). Plan Estratégico Institucional 2007-2011. Balanced Scorecard. Lima: AMAG.

(2008). Recomendaciones técnicas sustantivas a las universidades para la mejora de la formación de los estudiantes de las facultades de derecho que aspiran a la magistratura. Proyecto de Mejoramiento de los Servicios de Justicia (PMSJ) del Banco Mundial. Lima: AMAG.

LeÓn Pastor, Ricardo (1996). Diagnóstico de la cultura judicial peruana. Colección de Estudios Judiciales n. ${ }^{\circ}$ 1. Lima: AMAG. Miranda, Raúl (2007). Informe final sobre los nuevos perfiles formativos de jueces, fiscales y aspirantes a la magistratura. Proyecto de Apoyo a la Reforma del Sistema de Justicia del Perú, Jusper. Comunidad Europea. Lima: AMAG.

Salas Arenas, Jorge Luis (2003). Bases para la racionalización de la carga jurisdiccional: justicia en el reparto de la tarea de administrar justicia. Serie Reforma Judicial n. ${ }^{\circ}$ 1. Lima: AMAG.

Yépez SÁnchez, Miguel (2000). Ética judicial. Lima: Tarea Asociación Gráfica Educativa. 


\section{AGENCIA DE LOS ESTADOS UNIDOS PARA EL DESARROLLO INTERNACIONAL (USAID)}

Agencia de los Estados Unidos para el Desarrollo InternaCIONAL (USAID) (1996). Lecciones aprendidas: ponencias presentadas en la segunda mesa redonda sobre reforma judicial. Virginia: USAID/BID/NSCS.

(2003). Modernización del sistema de justicia comercial. Plan de Trabajo. Lima: USAID-Iris Center Perú/Universidad de Maryland. (2004). Proyecto justicia comercial. Lima: USAID-Iris Center Perú.

(2005). Impacto de la administración de justicia en la economía: análisis y principales indicadores. Lima: USAID.

\section{ASOCIACIÓN DE JUECES PARA LA JUSTICIA Y DEMOCRACIA (JUSDEM)}

Asociación DE Jueces para LA Justicia Y Democracia (JUSDEM) (2004a). Propuesta de reforma constitucional en el tema de impartición de justicia. Lima: JUSDEM.

(2004b). Propuestas de reforma judicial sobre Ley Orgánica del Poder Judicial, justicia contenciosa administrativa, de familia e infancia, laboral y comunal. Lima: JUSDEM.

(2007). Independencia judicial. Visión y perspectivas. Coord.

Roxana Jiménez Vargas-Machuca. Lima: JUSDEM/Fundación Nacional para la Democracia (NED).

\section{BANCO INTERAMERICANO DE DESARROLLO (BID)}

Banco Interamericano de Desarrollo (BID) (1996). Programa de modernización de la administración de justicia. Lima: Poder Judicial/BID.

(1997). Mejoramiento del acceso a la justicia. República del Perú. Washington D. C.: BID. 
(2002). Programa de Mejoramiento de Acceso a la Justicia. Informe de evaluación final del funcionamiento administrativojurisdiccional de los Módulos Básicos de Justicia. Lima: BID. (2009a). Apoyo a la preparación del Programa de modernización del sistema de administración de justicia para la mejora de los servicios brindados a la población peruana (PMSAJ). Washington D. C.: BID.

(2009b). Programa de modernización del sistema de administración de justicia para la mejora de los servicios brindados a la población peruana (PMSAJ). Washington D. C.: BID.

Herrero, Álvaro y Henderson, Keith (2003). El costo de las resoluciones de conflictos en la pequeña empresa. El caso de Perú. Washington D. C.: BID.

\section{BANCO MUNDIAL (BM)}

Banco Mundial (BM) (1996). Proyecto de administración de justicia en el Perú. Lima: BM.

(2003). Propuesta de reestructuración del Poder Judicial: matriz integral. Preparación del Proyecto de Modernización de los Servicios de Justicia. Lima: BM.

Bhansali, Lisa L. (2006). «Justicia». En Giugale, Marcelo, FretesCibils, Vicente y Newman, John. Perú. La oportunidad de un país diferente: próspero, equitativo y gobernable. Lima: BM, 789-808.

Casana, Patricia (2008). Informe. Consultoría Perfil de competencias de jueces y fiscales. Proyecto de Mejoramiento de los Servicios de Justicia (PMSJ). Lima: BM.

Gonzáles Mantilla, Gorki, Serván, Jean Carlo, López, Luciano y Burgos, Hernando (2002). El sistema judicial en el Perú: un 
enfoque analítico a partir de sus usos y usuarios. Informe para el Banco Mundial. Lima: BM.

Lechuga Pino, Ernesto (2006). Formulación de una propuesta integral de los perfiles de jueces y fiscales. Proyecto de Mejoramiento de los Servicios de Justicia (PMSJ). Lima: BM.

Shack Yalta, Nelson (coord.) (2008). Caminos de justicia: libro memoria. Roads of justice memoirs. Lima: Unidad de Coordinación del Proyecto de Mejoramiento de los Servicios de Justicia.

\section{CENTRO DE ESTUDIOS DE DERECHO Y SOCIEDAD (CEDYS)}

Centro de Estudios de Derecho y Sociedad (Cedys) (1979). La justicia de paz no letrada. Diagnóstico. Lima: Cedys.

Ciudad, Teresa y Zarzar, Alonso (1980). El juez peruano en el banquillo. Lima: Cedys.

PÁsARA, Luis (1982). Jueces, justicia y poder en el Perú. Lima: Cedys.

\section{CENTRO DE ESTUDIOS FINANCIEROS DE ASBANC (CEFI)}

Toche, Fátima e Iriarte, Erick (2010). Propuesta integral para la implementación de un sistema de expediente digital para los juzgados comerciales. Lima: Centro de Estudios Financieros de ASBANC.

\section{CENTRO DE ESTUDIOS Y PROMOCIÓN DEL DESARROLLO (DESCO)}

Centro de Estudios y Promoción del Desarrollo (Desco) (1976a). Formación y conceptualización jurídica de los magistrados. Estudio por convenio con la Comisión de Reforma Judicial del Poder Judicial. Lima: Desco.

(1976b). Cambios en la administración de justicia 1968-1975. Estudio por convenio con la Comisión de Reforma Judicial del Poder Judicial. Lima: Desco. 
(1976c). Costos en la administración de justicia. Estudio por convenio con la Comisión de Reforma Judicial del Poder Judicial. Lima: Desco.

(1977a). Planteamiento general del problema de justicia fuera del aparato formal. Estudio por convenio con la Comisión de Reforma Judicial del Poder Judicial. Lima: Desco. (1977b). Ubicación social del administrador de justicia. Estudio por convenio con la Comisión de Reforma Judicial del Poder Judicial. Lima: Desco.

(1977c). Informe final. Estudio por convenio con la Comisión de Reforma Judicial del Poder Judicial. Lima: Desco.

(s. f.). Organización de la administración de justicia. Estudio por convenio con la Comisión de Reforma Judicial del Poder Judicial. Lima: Desco.

(s. f.). Procesamiento jurídico de conflictos sociales. Estudio por convenio con la Comisión de Reforma Judicial del Poder Judicial. Lima: Desco.

Rubio Correa, Marcial (1999). Quítate la venda para mirarme mejor. La reforma judicial en el Perú. Lima: Desco.

\section{COLEGIO DE ABOGADOS DE LIMA (CAL)}

Colegio de Abogados de lima (CAL) (1932). Anteproyecto de Reforma del Poder Judicial y Exposición de motivos. Lima: Imprenta de Torres Aguirre.

(1988). Anteproyecto de Ley Orgánica del Poder Judicial. Lima: CAL.

(2004). Reforma del sistema judicial en el Perú. Aportes a la reforma del sistema judicial en el Perú. Congreso Internacional del Colegio de Abogados de Lima. Lima: Librería y Ediciones Jurídicas.

MacLean Ugarteche, Roberto G. (2006). Propuesta de la Comisión de Reforma Judicial del Colegio de Abogados de Lima para el 
desarrollo de un Plan de trabajo y actividades en la Academia de la Magistratura (2006-2011). Lima: CAL.

\section{COMISIÓN ANDINA DE JURISTAS (CAJ)}

Bernales, Enrique et al. (2005). Reforma del Estado, reforma de la Constitución. Lima: CAJ/Fundación Konrad Adenauer.

Comisión Andina de Juristas (CAJ) (1997). Proyecto de indicadores estadísticos judiciales de la Administración de Justicia. Lima: CAJ.

(1998). Perfil del litigante. Lima: CAJ.

(1999a). Indicadores judiciales. Lima: CAJ.

(1999b). Reforma del Estado y derechos humanos. Lima: CAJ. (1999c). Gente que hace justicia: la justicia de paz. Lima: CAJ.

(1999d). Formación y capacitación de magistrados: el caso peruano. Lima: CAJ.

(1999e). Formación de magistrados y derechos humanos. Lima: CAJ.

(2002). «Reforma judicial en el Perú en el contexto de transición democrática». II Foro temático regional. Gobernabilidad para el empoderamiento de los pobres. Lima: CAJ.

(2003). Corrupción judicial: mecanismos de control y vigilancia ciudadana. Lima: CAJ.

De Belaunde López de Romaña, Javier (1994). «Elección popular de jueces». La Constitución de 1993: análisis y comentarios. Lima: CAJ.

Mendoza CÁnePa, Raúl (2005). Independencia judicial: el juez, ¿un modelo para armar? Lima: CAJ.

Siles Vallejos, Abraham (2002). Corrupción en el Poder Judicial peruano: marco conceptual. Lineamientos de una propuesta de participación ciudadana para su control y erradicación. Lima: CAJ. 
Ruiz BAllón, Antonio (2009). Auditoría social al sistema de justicia: una práctica, una propuesta. Lima: CAJ.

\section{COMISIÓN DE LA VERDAD Y RECONCILIACIÓN (CVR)}

Comisión de la Verdad y Reconciliación (CVR) (2003a). Informe final. Poder Judicial. Conclusiones. Recomendaciones. Tomos I, III y IX. Lima. (2003b). Administración de justicia. Materiales para el informe final. Lima.

(2004). Hatun willakuy. Versión abreviada del informe final de la Comisión de la Verdad y Reconciliación. Lima: CVR.

\section{COMISIÓN ESPECIAL PARA LA REFORMA INTEGRAL DE LA ADMINISTRACIÓN DE JUSTICIA (CERIAJUS)}

Comisión Especial para la Reforma Integral de la AdminisTRACIÓN DE JUsticia (CERIAJUS) (2004a). Plan Nacional de Reforma Integral de la Administración de Justicia. Lima.

(2004b). Los problemas de la justicia en el Perú: hacia un enfoque sistémico. Diagnóstico interinstitucional. Lima: Secretaría Técnica y Comisión Andina de Juristas/CERIAJUS.

(2004c). La CERIAJUS: preguntas y respuestas. Lima: Poder Judicial/Ministerio Público/Ministerio de Justicia/Comisión Andina de Juristas/Consorcio Justicia Viva/Iris Center Perú.

\section{COMISIÓN INTERNACIONAL DE JURISTAS (CIJ)}

Comisión Internacional de Juristas (CIJ) (1989). Perú: la independencia del Poder Judicial. Informe de misión elaborado por José Martín Pallín. Lima: Centro para la Independencia de Jueces y Abogados (CIJA-CIJ)/CAJ. 
García Sayán, Diego (ed.). (1991). Poder Judicial y democracia. Lima: Centro para la Independencia de Jueces y Abogados (CIJA-CIJ)/CAJ.

(1994). Sobre la administración de justicia en el Perú. Lima: CIJ/IDL.

\section{COMISIÓN VILLARÁN}

Comisión Villarán (1931). «El Poder Judicial». Exposición de motivos del Anteproyecto de Constitución del Estado 1931. Lima: Imprenta Torres Aguirre.

\section{COMUNIDAD EUROPEA}

Comunidad Europea (2008). Proyecto de Apoyo a la Reforma del Sistema de Justicia del Perú, Jusper. Comunidad Europea. Más justicia para todos los peruanos. Lima: Jusper.

\section{CONGRESO DE LA REPÚBLICA DEL PERÚ}

Congreso de la República del Perú (2005). Avances en la implementación de las propuestas planteadas por la CERIAJUS. Lima: Comisión Especial de Estudio del Plan Nacional de Reforma Integral de la Administración de Justicia.

(2007). Dictamen recaído en los Proyectos de Ley $n .^{\circ}$ 116/2006$C R, \quad 131 / 2006-C R, \quad 220 / 2006-C R, \quad 322 / 2006-C R, \quad 331 / 2006-$ CR, 613/2006-CR, 665/2006-CR, 704/2006-CR, 734/2006-CR, 833/2006-CR, 841/2006-PE, 888/2006-CR, que proponen reforma parcial de la Constitución en lo referente a la administración de justicia. Lima: Comisión de Constitución y Reglamento.

\section{CONSEJO LATINOAMERICANO DE DERECHO Y DESARROLLO}

Consejo latinoamericano de Derecho y Desarrollo (1977). Seminario sobre derecho y cambio social. Lecturas seleccionadas. Lima. 


\section{CONSORCIO JUSTICIA VIVA}

Bazán Seminario, César (2008). ¿Separando la paja del trigo? Destitución de jueces por el Consejo Nacional de la Magistratura entre el 2003 y el 2007. Lima: Consorcio Justicia Viva.

Consorcio Justicia Viva (2003a). Cambios en el sistema de justicia: entre la expectativa y la incertidumbre. Lima: Consorcio Justicia Viva.

(2003b). Propuesta para la reforma constitucional peruana en el tema de impartición de justicia. Lima: Consorcio Justicia Viva.

(2003c). Comentarios a los informes de los grupos de trabajo de la Comisión de Reestructuración del Poder Judicial. Lima: Consorcio Justicia Viva.

(2004a). Plan de Reforma de la Administración de Justicia de la CERIAJUS: el acuerdo por la justicia que debemos respetar. Lima: Consorcio Justicia Viva.

(2004b). Hacia la refundación del sistema de justicia. Plan Nacional de Reforma Integral de la Administración de Justicia. Comisión Especial para la Reforma Integral de la Administración de Justicia (CERIAJUS). Lima: Consorcio Justicia Viva.

(2004c). Comentarios a los informes de la Comisión de Reestructuración. Lima: Consorcio Justicia Viva.

(2004d). Bases para la regulación de la carrera judicial y fiscal. Lima: Consorcio Justicia Viva.

(2005a). Sala Penal Nacional. El trabajo en los casos de terrorismo. Lima: Consorcio Justicia Viva.

(2005b). Carrera judicial: una propuesta de reforma verdaderamente estructural. Lima: Consorcio Justicia Viva. (2005c). Balance de la justicia 2005: reformar la reforma. Lima: Consorcio Justicia Viva. 
(2006). Reforma constitucional en materia de justicia: una propuesta de regulación desde la sociedad civil. Lima: Consorcio Justicia Viva.

(2008a). La aplicación del nuevo Código Procesal Penal en Huaura. Una experiencia latinoamericana positiva. Lima: Consorcio Justicia Viva.

(2008b). Balance de la justicia en el 2008. Hay cambios y cambios... y sin reforma. Lima: Consorcio Justicia Viva.

(2008c). Fortalezas y debilidades de la ley de la carrera judicial. Informe técnico. Lima: Consorcio Justicia Viva.

Cubas Villanueva, Víctor (2004). El nuevo Código Procesal: ¿revolución penal? Lima: Consorcio Justicia Viva.

DARgent Bocanegra, Eduardo (2005). Justicia es igualdad: idiosincrasia judicial y reforma de la justicia. Lima: Consorcio Justicia Viva.

De la Jara Basombrío, Ernesto (2004a). ¿Se puede reformar el Poder Judicial? Lima: Consorcio Justicia Viva.

(2004b). ¿Qué se puede esperar de la Corte Suprema y de su nuevo presidente? Lima: Consorcio Justicia Viva.

De la Jara Ernesto, Lovatón, David, Siles, Abraham y Rivera, Carlos (2005). La reforma del sistema de justicia: ¿qué reforma? 2004-2005. Lima: Consorcio Justicia Viva.

Esteban Delgado, Sara y Silva Del Carpio, Cruz (2004). El nombramiento imposible: concurso a magistrados supremos (a propósito de la convocatoria del 2004). Lima: Consorcio Justicia Viva.

Gamarra Herrera, Ronald, Ramírez Varela, Lilia y Silva Del CARpio, Cruz (2007). Balance del subsistema anticorrupción. A seis años de su creación (2000-2006). Lima: Consorcio Justicia Viva. 
Guerrero Alarcón, Lucy Mariel (2005). Propuesta comunicativa para mejorar la administración de justicia: construyendo la agenda pública de la justicia eficaz, accesible e independiente. Lima: Consorcio Justicia Viva.

Hernández Breña, Wilson (2003a). Indicadores sobre administración de justicia. Mapa judicial, presupuesto y eficiencia en el desempeño judicial. Lima: Consorcio Justicia Viva.

(2003b). Jueces para la justicia y democracia. Lima: Consorcio Justicia Viva.

(2004). El presupuesto del Poder Judicial 2003, 2004 y 2005: precariedad y ausencia de reforma. Lima: Consorcio Justicia Viva.

(2006). Carga y descarga procesalen el Poder Judicial, 1996-2005. De lo general a lo particular, de lo cotidiano a lo preocupante. Lima: Consorcio Justicia Viva.

(2007a). Del discurso a la práctica en el proyecto de presupuesto judicial 2007. Lo que el Poder Judicial solicitó y lo que se asignaría. ¿Promesa de avance o estancamiento? Lima: Consorcio Justicia Viva.

(2007b). 13 mitos sobre la carga procesal. Anotaciones y datos para la política judicialpendiente en la materia. Lima: Consorcio Justicia Viva.

(2008). La carga procesal bajo la lupa: por materia y tipo de órgano jurisdiccional. Lima: Consorcio Justicia Viva.

La Rosa Calle, Javier, Salazar Montoya, Jimena y Zavala Respaldiza, Zarela (2008). Acceso a la justicia y seguridad ciudadana: un balance de los Juzgados de Paz Letrados en comisarías. Lima: Consorcio Justicia Viva.

O’Brien NeIra, Eduardo (2003). El presupuesto de la administración de justicia: análisis de los cuatro pliegos vinculados al sistema. Lima: Consorcio Justicia Viva. 
Palacios, Rosa María (2004). Entrevistas de Rosa María Palacios sobre administración de justicia: Javier de Belaunde, Fausto Alvarado y J. Francois Patthey. Lima: Consorcio Justicia Viva.

PÁsARA, Luis (2003). Idoneidad en los criterios de selección utilizados por el Consejo Nacional de la Magistratura. Lima: Consorcio Justicia Viva.

(2005). Los abogados de Lima en la administración de justicia: una aproximación preliminar. Lima: Consorcio Justicia Viva.

PÁsAra, Luis (comp.) (2004). En busca de una justicia distinta. Experiencias de reforma en América Latina. Lima: Consorcio Justicia Viva.

Soberón, Ricardo y CABADA, Guillermo (2004). Justicia en Lima Norte: un instrumento de alerta de gestión jurisdiccional. Lima: Consorcio Justicia Viva.

Villavicencio Ríos, Alfredo y Bazán Seminario, César (2004). La reestructuración silenciosa. La labor del Consejo Nacional de la Magistratura en la selección y nombramiento de magistrados noviembre del 2000-marzo del 2004. Lima: Consorcio Justicia Viva.

\section{COOPERACIÓN ALEMANA AL DESARROLLO (GTZ)}

Cooperación Alemana al Desarrollo (GTZ) (2003). Proyecto Apoyo a la Consolidación de la Reforma del Sistema Procesal Penal y de la Administración de la Justicia. Ministerio Federal Alemán de Cooperación Económica y Desarrollo (BMZ). Lima.

\section{COORDINADORA NACIONAL DE DERECHOS HUMANOS (CNDH)}

Coordinadora Nacional de Derechos Humanos (CNDH) (1995). Informe sobre la independencia e imparcialidad de los jueces y abogados en el Perú. Lima. 


\section{DEFENSORÍA DEL PUEBLO}

Defensoría del Pueblo (1999). El derecho a un proceso sin dilaciones: el caso de la Sala Constitucional y Social de la Corte Suprema de Justicia. Serie Informes Defensoriales. Informe n. ${ }^{\circ}$ 32. Lima: Defensoría del Pueblo.

(2000). El sistema penal juvenil en el Perú. Serie Informes Defensoriales. Informe n. ${ }^{\circ}$ 51. Lima: Defensoría del Pueblo. (2006). Propuestas básicas de la Defensoría del Pueblo para la reforma de la justicia en el Perú. Generando consensos sobre qué se debe reformar, quiénes se encargarán de hacerlo y cómo lo harán. Serie Informes Defensoriales. Informe n. ${ }^{\circ}$ 109. Lima: Defensoría del Pueblo. (2007a). Justicia de Paz Letrada en comisarías: una propuesta para enfrentar la inseguridad ciudadana. Serie Informes Defensoriales. Informe n. ${ }^{\circ} 119$. Lima: Defensoría del Pueblo. (2007b). Propuestas para una reforma de la justicia contenciosoadministrativa desde la perspectiva del acceso a la justicia. Serie Informes Defensoriales. Informe n. ${ }^{\circ} 121$. Lima: Defensoría del Pueblo.

\section{DEMUS. ESTUDIO PARA LA DEFENSA DE LOS DERECHOS DE LA MUJER}

DEMUS. ESTUdio PARA LA DEFENSA DE LOS DERECHOS DE LA MUJER (2007). Para una justicia diferente. Temas para la reforma judicial desde y para las mujeres. Lima: DEMUS.

(2010). Justicia de género. Reforma procesal peruana y derechos de mujeres víctimas de violencias de género: desafío pendiente. Lima: DEMUS.

\section{DIARIO EL COMERCIO}

El Comercio (2000). «Poder Judicial. Corte Suprema». Propuestas para una agenda de gobierno 2000. Lima: El Comercio. 
(2001). «Poder Judicial». Propuestas para una agenda de gobierno 2001. Lima: El Comercio.

(2006). «Poder Judicial». Propuestas para una agenda de gobierno 2006. Lima: El Comercio.

\section{FORO DE ESTUDIOS SOBRE LA ADMINISTRACIÓN DE JUSTICIA (FORES)}

Chayer, Héctor Mario (2008). «Comisión Andina de Juristas y su proyecto Auditoría Social al Sistema de Justicia». Ética judicial y sociedad civil. Técnicas de incidencia. Montevideo: FORES/ Fundación Konrad Adenauer, 84-89.

\section{FUNDACIÓN FRIEDRICH NAUMANN (FNST)}

BRANDT, Hans-Jürgen (1986). Justicia popular: nativos y campesinos. Lima: Corte Suprema de Justicia de la República y FNST. (1987). La justicia de paz y el pueblo. Lima: Corte Suprema de Justicia de la República y FNST.

(1990). En nombre de la paz comunal: un análisis de la justicia de paz en el Perú. Lima: Corte Suprema de Justicia de la República y FNST.

Chunga Lamonja, Fermín G. (1986). La justicia de paz en el Perú. Lima: Corte Suprema de Justicia de la República y FNST.

Fundación FRIEDRICH NAUMANn (FNST) (1986). Problemática del menor y administración de justicia. Lima: Corte Suprema de Justicia de la República y FNST.

\section{FUNDACIÓN INTERNACIONAL PARA SISTEMAS ELECTORALES (IFES)}

Elena, Sandra, Herrero, Álvaro y Herderson, Keith (2004). Barreras para la ejecución de sentencias judiciales en el Perú. Triunfar en las cortes es solo la mitad de la batalla: una 
perspectiva desde la pequeña empresa y otros usuarios. Lima: IFES/USAID.

\section{GRUPO DE TRABAJO DE ALTO NIVEL PARA LA MODERNIZACIÓN DEL SISTEMA NACIONAL DE ADMINISTRACIÓN DE JUSTICIA (GTAN)}

Grupo de Trabajo de Alto Nivel para la Modernización del Sistema Nacional de Administración de Justicia (GTAN) (2001). Modernización del Sistema Nacional de Justicia: plan estratégico y lineamientos para su implementación. Lima: Secretaría Técnica GTAN.

(2003). Plan estratégico priorizado: hacia una agenda de cambios en el sistema de justicia. Lima: Secretaría Técnica GTAN.

\section{INSTITUTO APOYO}

Eyzaguirre, Hugo y Calderón, Carlos (2002). Poder Judicial y micro y pequeña empresa: impacto y posibles soluciones. Documento de Trabajo n. ${ }^{\circ}$ 8. Lima: Instituto Apoyo.

Eyzaguirre, Hugo, Polarollo, Pierina y Andrade, Raúl (2000). La estructura de incentivos y las ineficacias en tres procesos civiles: juicios por títulos ejecutivos vencidos, juicios por alimentos y ejecución forzada de bienes. Lima: Instituto Apoyo.

Instituto Apoyo (1993). Estudios de opinión sobre el sistema judicial. Evaluación del sistema judicial-opinión pública y evaluación del sistema judicial-agraciados. Lima: Instituto Apoyo.

(2000). Reforma del Poder Judicial. Task Forces: agenda para la primera década. Fundación Nacional para la Democracia (NED) y Agencia de los Estados Unidos para el Desarrollo Internacional (USAID). Lima: Instituto Apoyo. 
Salhuana, Róger, Andrade, Raúl y Eyzaguirre, Hugo (1998). El impacto del Poder Judicial en las decisiones empresariales en el Perú. Lima: Instituto Apoyo.

\section{INSTITUTO DE DEFENSA LEGAL (IDL)}

Instituto de Defensa Legal (1996). Desafíos de la justicia en el Perú. Lima: IDL.

(1999a). Justicia de paz. Propuesta de Ley. Lima: IDL.

(1999b). Justicia de paz. El otro Poder Judicial. Lima: IDL.

(1999c). Justicia de paz en debate. Lima: IDL.

(2002). Memoria de la jornada de reflexión sobre justicia de paz. Lima: IDL.

(2011a). Balance de la justicia 2009-2010. ¿Cómo estuvo la justicia en el Perú? Lima: IDL.

(2011b). La reforma judicial pendiente. Hoja de ruta. Lima: IDL.

(2011c). Balance de la justicia y de los derechos de los pueblos indígenas en el Perú del 2011. Lima: IDL.

Franco, Rocío y González, María Alejandra (2009). Las mujeres en la justicia comunitaria: víctimas, sujetos y actores. Lima: IDL.

LA RosA, Javier (coord.) (2007). Acceso a la justicia en el mundo rural. Lima: IDL.

Lovatón, David (2002). Cambios en la justicia peruana y la sociedad civil (1990-2002). Informe para la Fundación Ford. Lima: IDL.

Lovatón, David y Ardito, Wilfredo (2002). Justicia de paz: nuevas tendencias y tareas pendientes. Lima: IDL.

Montoya, Iván (1997). El Poder Judicial y el Estado democrático del derecho en el Perú. Lima: IDL.

PÁsARA, Luis (2010). Calidad de la producción en la reforma procesal penal. Una exploración empírica en Huaura. Lima: IDL. 
Salas Villalobos, Sergio (2001). Justicia democrática. Bases de política institucional para la consolidación del Poder Judicial. Lima: IDL.

Siles Vallejos, Abraham (1999). La justicia de paz y su labor esencialmente conciliadora. Un análisis de actas de conciliación. Comisión Europea. Lima: IDL.

Siles, Abraham, Gamarra, Ronald, Ramírez, Lilia, Silva, Cruz y Torres, Natalia (2005). Lucha anticorrupción: urgente necesidad de enmienda. Lima: IDL.

\section{INSTITUTO DE PRENSA Y SOCIEDAD (IPYS)}

Fundación para el Debido Proceso Legal (2007). «Perú». Comparando transparencia. Un estudio sobre el acceso a la información en el Poder Judicial. Washington D. C.: Fundación para el Debido Proceso Legal (DPLF), 187-210.

\section{INSTITUTO PERUANO DE ECONOMÍA (IPE)}

GARCíA, Mauricio (2003). La reforma de la administración de justicia. Marzo 1999. Lima: IPE.

\section{MINISTERIO DE JUSTICIA (MINJUS)}

De Belaunde López de Romaña, Javier (1993). Calidad de la educación legal y rol de los abogados en la administración de justicia. Lima: MINJUS/PNUD.

MoAnes, Eduardo (ed.) (1994). Foro: nuevas perspectivas para la reforma integral de la administración de justicia en el Perú. Lima: MINJUS/PNUD.

Ministerio de Justicia (MINJUS) (1995). Apuntes para una visión integral de la administración de justicia en el Perú. Comisión de Reestructuración Integral de la Administración de Justicia en el Perú. Lima: MINJUS. 
(2001a). Informe de la Misión Fortalecimiento Institucional de la Justicia en el Perú. Lima: MINJUS/PNUD.

(2001b). Plan Justicia. Lima: MINJUS.

(2001c). Un Perú sin corrupción: condiciones, limitaciones y recomendaciones para la lucha contra la corrupción. Lima: MINJUS/INA.

(2001d). Documento final de trabajo. Comisión de Estudio de las Bases de la Reforma Constitucional. Lima: MINJUS/ Konrad Adenauer Stiftung.

(2001e). De la exclusión a la confianza mediante el acceso a la justicia. Informe de la Misión Fortalecimiento Institucional de la Justicia en el Perú. Lima: MINJUS/PNUD.

(2007). Informe anual de la implementación del Nuevo Código Procesal Penal en el Distrito Judicial de Huaura. Lima: MINJUS.

PÁsARA, Luis (2004). La enseñanza del derecho en el Perú. Su impacto sobre la administración de justicia. Lima: MINJUS.

\section{PODER JUDICIAL DEL PERÚ (PJ)}

Ardito Vega, Wilfredo (2011). La promoción del acceso a la justicia en las zonas rurales. Lima.

Balbuena Palacios, Patricia (2007). Género y multiculturalidad. Proyecto de Mejoramiento de los Servicios de Justicia. Banco Mundial. Lima: Poder Judicial.

Bustamante Cisneros, Ricardo (1959). Independencia y reforma del Poder Judicial. Discurso leído al asumir la presidencia de la Corte Suprema en la ceremonia de apertura del año judicial de 1959. Lima: Poder Judicial.

Cussiánovich Villarán, Alejandro, Tello Gilardi, Janet y Sotelo Trinidad, Manuel (2007). Violencia intrafamiliar. Proyecto de Mejoramiento de los Servicios de Justicia. Banco Mundial. Lima: Poder Judicial. 
Domínguez Haro, Helder (2011). Informe sobre reforma del Poder Judicial. Lima: Poder Judicial.

Eguiguren, Luis Antonio (1953). Historia de la Corte Suprema de Justicia de la República. Lima: Poder Judicial.

Estrada Vera, Williams (2007). Servicio y atención al cliente. Proyecto de Mejoramiento de los Servicios de Justicia. Lima: Banco Mundial/Poder Judicial.

Gjurinovic Canevaro, Pedro (ed.) (2008). Joya de la justicia. Lima: Interfórum.

Junco Supa, Jenny Elsa y Rosas Ballinas, María Isabel (2007). Género. Lima: Proyecto de Mejoramiento de los Servicios de Justicia.

MejÍA Mori, Beatriz (1996). Reformas legales para la reforma de la administración de justicia. Lima: PNUD/Poder Judicial.

Ormachea Choque, Iván y Vargas Solís, Rocío (1998). Retos y posibilidades de la conciliación en el Perú: primer estudio cualitativo. Lima: Consejo de Coordinación Judicial.

Pezúa Vivanco, David (1999). Reforma judicial: mensajes, perspectivas para el tercer milenio. Lima: Secretaría Ejecutiva del Poder Judicial.

Poder Judicial del Perú (1976a). Comisión de Reforma Judicial. N. ${ }^{\circ}$ 1. Lima: Poder Judicial. (1976b). Comisión de Reforma Judicial. N. ${ }^{\circ}$ 2. Lima: Poder Judicial.

(1977). Comisión de Reforma Judicial. N. ${ }^{\text {3 3. Lima: Poder }}$ Judicial.

(1978). Anteproyecto de normas constitucionales sobre la administración de justicia. Lima: Comisión de Reforma Judicial. 
(1982). Anteproyecto de Bases para la nueva Ley Orgánica del Poder Judicial. Lima: Poder Judicial.

(1985a). Proyecto Instituto Académico de la Magistratura. Lima: Poder Judicial.

(1985b). Foro nacional sobre realidad sociojurídica de la justicia de paz en el Perú: la capacitación como estrategia promocional. Lima: Poder Judicial.

(1986). Políticas de gestión institucional de la Corte Suprema de Justicia. Lima: Poder Judicial.

(1988). Diagnóstico sobre la administración de justicia en el Perú. Lima: Poder Judicial.

(1992). Anteproyecto de reforma constitucional del Poder Judicial. Lima: Comisión de Reforma Constitucional.

(1994). Proyecto Plan de mejora del gasto social básico del Poder Judicial. Lima: Poder Judicial.

(1997a). Acceso a la justicia. Lima: Poder Judicial.

(1997b). Reforma judicial. Exposiciones del seminario taller. Lima: Poder Judicial.

(1997c). Poder Judicial: plan estratégico modernización y reforma. Lima: Poder Judicial.

(1997d). Reforma y modernización del Poder Judicial. Lima: Poder Judicial.

(1997e). Avances del proceso de reforma y modernización. Lima:

Poder Judicial.

(1998a). Reforma judicial: evaluación y perspectivas de desarrollo. Lima: Poder Judicial.

(1998b). I Encuentro de Decanos de Facultades de Derecho, Arequipa. Lima: Poder Judicial.

(1999a). Reforma judicial: gestión administrativa, soporte de la función jurisdiccional. Lima: Secretaría Ejecutiva del Poder Judicial.

(1999b). Fundamentos estructurales de la reforma del Poder Judicial. Lima: Secretaría Ejecutiva del Poder Judicial. 
(1999c). Reflexiones sobre ética judicial: ponencias $y$ conclusiones. Cuadernos de Debate Judicial. Lima: Consejo de Coordinación Judicial.

(2000a). Antología de la reforma del Poder Judicial. Lima: Poder Judicial.

(2000b). La reforma del Poder Judicial. La reforma en cifras.

Informe al 30 de setiembre de 1999. Lima: Poder Judicial.

(2000c). La reforma jurisdiccional en el Perú: un impulso al tercer milenio. Lima: Comisión Ejecutiva del Poder Judicial.

(2000d). Anteproyecto de Ley Orgánica del Poder Judicial (exposición de motivos y articulado). Lima: Poder Judicial. (2000e). Proceso de reforma y modernización del Poder Judicial. Lima: Poder Judicial.

(2001a). Propuestas de bases para un diseño del Poder Judicial. Lima: Consejo Transitorio del Poder Judicial.

(2001b). Políticas de moralización, eticidad y anticorrupción. Informe final. Lima: Consejo Transitorio del Poder Judicial. (2001c). Anteproyecto de la Nueva Ley Orgánica del Poder Judicial. Elaborado por una Comisión Mixta del Congreso de la República y la Corte Suprema de Justicia. Lima: Poder Judicial.

(2002a). Informe final. Programa de Mejoramiento del Acceso a la Justicia. Banco Interamericano de Desarrollo. Lima: Poder Judicial.

(2002b). Plan Estratégico 2002-2006. Sala Plena de la Corte Suprema de Justicia. Lima: Poder Judicial.

(2003a). Estudio de factibilidad del Proyecto Mejoramiento de los Servicios de Administración de Justicia. Lima: Poder Judicial.

(2003b). Resumen ejecutivo del Proyecto Mejoramiento de los Servicios de Administración de Justicia. Lima: Poder Judicial. 
(2003c). Hacia la refundación del Poder Judicial. La nueva visión del cambio en la justicia. Acuerdo Nacional por la Justicia. Lima: Poder Judicial.

(2003d). Políticas de Estado para el Poder Judicial: de la crisis a la salida institucional. Acuerdo Nacional por la Justicia. Lima: Poder Judicial.

(2003e). Informe de actividades. Acuerdo Nacional por la Justicia. Lima: Poder Judicial.

(2003f). Lineamientos de trabajo de la Comisión de Magistrados para la Reestructuración del Poder Judicial. Lima: Poder Judicial.

(2003g). Informe final de la Secretaría Técnica. Comisión de Magistrados para la Reestructuración del Poder Judicial. Lima: Poder Judicial.

(2003h). Informe final del Grupo de Trabajo de Reestructuración de Órganos de Gobierno y de Gestión Judicial. Comisión de Magistrados para la Reestructuración del Poder Judicial. Lima: Poder Judicial.

(2003i). Informe final del Grupo de Trabajo Temático de Reforma de la Justicia Civil. Comisión de Magistrados para la Reestructuración del Poder Judicial. Lima: Poder Judicial. (2003j). Informe final del Grupo de Trabajo Temático de la Modernización del Despacho Judicial. Comisión de Magistrados para la Reestructuración del Poder Judicial. Lima: Poder Judicial.

(2003k). Informe final del Grupo de Trabajo Temático de Reforma de la Justicia Penal. Comisión de Magistrados para la Reestructuración del Poder Judicial. Lima: Poder Judicial. (20031). Informe final del Grupo de Trabajo sobre Política Anticorrupción y Ética Judicial. Comisión de Magistrados para la Reestructuración del Poder Judicial. Lima: Poder Judicial. 
(2003m). Informe final de la Comisión de Revisión de la Autógrafa de la Ley Orgánica del Poder Judicial. Lima: Poder Judicial.

(2003n). Informe final de la Comisión sobre Reforma de la Constitución Política del Estado. Lima: Poder Judicial. (2003ñ). Justicia y periodismo. Lima: Poder Judicial. (2004). Perfil. Proyecto de fortalecimiento, mejora y ampliación de los servicios del Poder Judicial en la subespecialidad comercial en el Distrito Judicial de Lima. Comisión de Juzgados Comerciales. Lima: Poder Judicial.

(2005a). Plan de Acción 2005-2006. Acciones priorizadas de Reestructuración Judicial. Lima: Poder Judicial. Corte Superior de Justicia de Lima.

(2005b). Marco conceptual del despacho judicial penal bajo la vigencia del nuevo Código Procesal Penal. Lima: Poder Judicial. Comisión de Coordinación Interinstitucional de la Justicia Penal.

(2005c). Evaluación y diagnóstico de la actual organización y funcionamiento del módulo corporativo civil, familia y laboral. Determinación de problemas y propuestas de solución. Lima: Poder Judicial.

(2006a). Ética y control de la corrupción. Lima: Poder Judicial. (2006b). Plan Estratégico Institucional 2007-2009 del Poder Judicial. Lima: Consejo Ejecutivo del Poder Judicial.

(2006c). Informe sobre el proyecto de sistematización y difusión electrónica de la jurisprudencia. Lima: Proyecto de Apoyo a la Reforma del Sistema de Justicia del Perú, Jusper. Comunidad Europea.

(2007a). Proyecto de Bases para el Plan Decenal de Modernización del Poder Judicial 2008-2017. Lima: Proyecto de Apoyo a la Reforma del Sistema de Justicia del Perú, Jusper. Comunidad Europea. 
(2007b). Técnicas de investigación de la corrupción en la administración de justicia. Proyecto de Mejoramiento de los Servicios de Justicia. Lima: Banco Mundial/Poder Judicial. (2008a). I Congreso Nacional de Magistrados del Poder Judicial. Lima: Fondo Editorial del Poder Judicial.

(2008b). Análisis y sistematización de las experiencias de capacitación a jueces de paz en el territorio nacional. Proyecto de Apoyo a la Reforma del Sistema de Justicia del Perú, Jusper. Comunidad Europea. Lima: Poder Judicial.

(2008c). Informe final. Diagnóstico situacional del servicio de justicia de paz letrada y de justicia de paz. Proyecto de Apoyo a la Reforma del Sistema de Justicia del Perú, Jusper. Comunidad Europea. Lima: Poder Judicial.

(2008d). Memoria institucional 2007-2008 Poder Judicial. Lima: Fondo Editorial del Poder Judicial.

(2008e). Propuesta de la OCMA para la planificación y diseño de las actividades a ser desarrolladas en el marco del Programa UMBRAL 2008-2010. Lima: Poder Judicial.

(2008f). Informe. Proyecto de Ley que instituye el sistema de medición de desempeño jurisdiccional. Lima: Poder Judicial. (2009a). II Congreso Nacional de Magistrados del Poder Judicial. Lima: Fondo Editorial del Poder Judicial.

(2009b). «Informe sobre propuesta de despacho judicial. Comisión para la modernización de despachos judiciales de las salas superiores y juzgados especializados y/o mixtos con excepción de la especialidad penal». III Congreso Nacional de Magistrados del Poder Judicial. Documentos de trabajo. Lima: Poder Judicial.

(2009c). La reforma del sistema procesal penal. Experiencias adquiridas en aplicación del nuevo sistema acusatorio adversarial. Lima: Poder Judicial. (2009d). El Poder Judicial y la economía peruana. Lima: Poder Judicial. 
(2010a). El Poder Judicial y la realidad peruana. Lima: Poder Judicial.

(2010b). III Congreso Nacional de Magistrados del Poder Judicial. Lima: Fondo Editorial del Poder Judicial.

(2010c). Memoria institucional 2009-2010 Poder Judicial. Lima: Fondo Editorial del Poder Judicial.

(2010d). Informe final de la Comisión de Control de Calidad y Productividad Jurisdiccional. Lima: Poder Judicial. (2010e). Lucha anticorrupción hoy: información para el control. Lima: Poder Judicial.

(2010f). «La reforma procesal en cifras. Una nueva visión de justicia. Corte Superior de Justicia de La Libertad». IV Congreso Nacional de Magistrados del Poder Judicial. Documentos de trabajo. Lima.

(2011a). Informe. Proyecto de Ley para fortalecer el sistema de control de la magistratura y crear la especialidad de jueces contralores. Lima: Poder Judicial.

(2011b). Congresos internacionales sobre justicia intercultural en pueblos indígenas, comunidades andinas y rondas campesinas. Construyendo un país con justicia social. Lima: Fondo Editorial del Poder Judicial/GIZ/Fundación Hanns Seidel. (2011c). «Agenda judicial de seguridad ciudadana». V Congreso Nacional de Magistrados del Poder Judicial. Documentos de trabajo. Lima: Poder Judicial.

(2011d). «Propuesta de Plan de Mejora de la Producción Jurisdiccional». V Congreso Nacional de Magistrados del Poder Judicial. Documentos de trabajo. Lima: Poder Judicial.

(2011e). «Descarga procesal: balance y propuesta». V Congreso Nacional de Magistrados del Poder Judicial. Documentos de trabajo. Lima: Poder Judicial.

(2011f). Primer taller de intercambio de experiencias. En el marco de la implementación de la nueva Ley Procesal de Trabajo. Lima: Poder Judicial. 
Ramos Núñez, Carlos (2008). Historia de la Corte Suprema de Justicia del Perú. Lima: Fondo Editorial del Poder Judicial.

Ramos Núñez, Carlos y Gálvez Montero, José Francisco (2008). Historia del Palacio Nacional de Justicia. Dos perspectivas. Lima: Fondo Editorial del Poder Judicial.

Ruska Maguiña, Carlos y Ledesma Narváez, Marianella (2007). La conciliación en familia. Proyecto de Mejoramiento de los Servicios de Justicia. Lima: Banco Mundial/Poder Judicial.

Salas Arenas, Jorge y Rubio Zeballos, Isaac (2004). Elementos para la planificación estratégica. Corte Superior de Justicia de Arequipa. Arequipa: Poder Judicial.

San Martín Castro, César (1996). Reforma del Poder Judicial. Eficiencia y carga procesal en el proceso penal: algunas referencias generales. Materiales de trabajo. Proyecto de Administración de Justicia en el Perú del Banco Mundial. Lima: Poder Judicial.

(2009). Homenaje a la Corte Suprema: historia y perspectivas. Lima: Fondo Editorial del Poder Judicial.

SHack, Nelson (comp.) (2008). Justicia y medios de comunicación: opinan los jueces. Proyecto de Mejoramiento de los Servicios de Justicia. Banco Mundial. Lima: Poder Judicial.

Shack, Nelson y Hernández Gálvez, Cristian (eds.) (2008). Herramientas modernas para el mejoramiento de la gestión judicial. Proyecto de Mejoramiento de los Servicios de Justicia. Banco Mundial. Lima: Fimart.

Siles Vallejos, Abraham (1998). Modernización y reforma de los sistemas de justicia en América Latina y el Caribe. Cuadernos de Debate Judicial. Lima: Poder Judicial.

Vega Mere, Yuri (2009). «Reflexiones sobre el rol del juez». III Congreso Nacional de Magistrados del Poder Judicial. Documentos de trabajo. Lima: Poder Judicial. 
Walde Jáuregui, Vicente (2011). Informe. Anteproyecto de Ley sobre Casación. Comisión de Trabajo encargada de elaborar el Anteproyecto de Ley sobre Casación. Lima: Poder Judicial.

\section{PONTIFICIA UNIVERSIDAD CATÓLICA DEL PERÚ (PUCP)}

Ciurlizza Contreras, Javier et al. (2005). Construyendo justicia. Verdad, reconciliación y procesamiento de violaciones de derechos humanos. Lima: Instituto de Democracia y Derechos Humanos (IDEHPUCP)/Programa Derechos, Inclusión y Desarrollo de OXFAM DFID/Fondo Editorial de la Pontificia Universidad Católica del Perú.

Pontificia Universidad Católica del Perú (PUCP) (1977). Informe final de investigación sobre la realidad y la reforma judicial del Perú. Estudio por convenio con la Comisión de Reforma Judicial del Poder Judicial. Instituto de Investigaciones Jurídicas. Lima: PUCP.

ReÁtegui, Félix (coord.) (2011). Estado y democratización en el Perú. Magistrados, docentes y su relación con la ciudadanía. Lima: Instituto de Democracia y Derechos Humanos (IDEHPUCP)/ Konrad Adenauer Stiftung.

\section{PONTIFICIA UNIVERSIDAD CATÓLICA DEL PERÚ (PUCP) Y ESAN}

ZolezzI, Lorenzo (coord.) (1991). Evaluación del sistema judicial peruano. 2 volúmenes. Lima: PUCP/ESAN/USAID.

\section{PRESIDENCIA DEL CONSEJO DE MINISTROS (PCM)}

Presidencia del Consejo de Ministros (PCM) (2008). Plan Nacional de Lucha contra la Corrupción 2008-2011: un diagnóstico sobre sus objetivos y acciones. Presentación pública el 23 de diciembre de 2008. Lima: PCM. 


\section{UNIVERSIDAD NACIONAL MAYOR DE SAN MARCOS (UNMSM)}

Carrión, Roque (1977a). Autonomía de la administración de justicia. Estudio por convenio con la Comisión de Reforma Judicial del Poder Judicial. Lima: UNMSM.

(1977b). Marcos teóricos y metodológicos para el control semántico de la jurisprudencia. Estudio por convenio con la Comisión de Reforma Judicial del Poder Judicial. Lima: UNMSM.

Universidad Nacional Mayor de San Marcos (1978). Proyecto de informática jurídica jurisprudencial. Estudio por convenio con la Comisión de Reforma Judicial del Poder Judicial. Lima: UNMSM.

\subsection{Bibliografía comparada}

Alzamora Valdez, Mario (1973). El Consejo Nacional de Justicia. Antecedentes en el Perú y legislación comparada. Lima: USAID.

Binder, Alberto M. у Овando, Jorge (2004). De las «repúblicas aéreas» al Estado de derecho. Debate sobre la marcha de la reforma judicial en América Latina. Buenos Aires: Ad-Hoc.

Bou, Marc (2004). El sistema de justicia en América Latina: entre las reformas y la inercia institucional. Documento de trabajo n. ${ }^{\circ}$ 4. Barcelona: Instituto Internacional de Gobernabilidad de Catalunya.

Correa Sutil, Jorge (ed.) (1993). Situación y políticas judiciales en América Latina. Escuela de Derecho de la Universidad Diego Portales. Santiago: Universidad Diego Portales.

Fix-Zamudio, Héctor et al. (1977). Función del Poder Judicial en los sistemas constitucionales latinoamericanos. México: UNAMInstituto de Investigaciones Jurídicas. 
Galindo, Pedro (2003). El peso externo. Calificaciones internacionales de los sistemas de justicia. Ponderaciones recientes para las Américas. Santiago.

Giraudo, Laura (ed.) (2008). Derechos, costumbres y jurisdicciones indígenas en la América Latina. Madrid: Centro de Estudios Políticos y Constitucionales.

Pásara, Luis (2004). Reformas del sistema de justicia en América Latina: cuenta y balance. México: UNAM-Instituto de Investigaciones Jurídicas.

(2006). «La cooperación internacional en materia de justicia en el ámbito latinoamericano». Viejas y nuevas alianzas entre América Latina y España: Encuentro de Latinoamericanistas Españoles, 1233-1251.

(2010). Ley, justicia y sociedad en América Latina. México: UNAM.

PÁsAra, Luis (ed.) (2007). Los actores de la justicia latinoamericana. Salamanca: Ediciones de la Universidad de Salamanca.

Roos, Stefanie Ricarda y Woischnik, Jan (2005). Códigos de ética judicial: un estudio de derecho comparado con recomendaciones para los países latinoamericanos. Montevideo: Konrad Adenauer Stiftung.

SAgüÉs, Néstor Pedro (1978). Reforma judicial. Buenos Aires: Astrea. (1994). «Variables y problemática del Consejo de la Magistratura en el reciente constitucionalismo latinoamericano». En Comisión Andina de Juristas. La Constitución de 1993: análisis y comentarios. Lima: CAJ.

Salas Villalobos, Sergio (2006). Introducción de la cultura organizacional para las reformas judiciales. Influencias teóricas en la Región Latinoamericana. Lima: Fondo Editorial de la Universidad Alas Peruanas. 
SouzA, Mariana (2007). «Breve panorama de la reforma judicial en América Latina: objetivos, desafíos y resultados». En LorA, Eduardo (ed.). El estado de las reformas del Estado en América Latina. Washington D. C.: Banco Mundial/Mayol Ediciones.

\section{AGENCIA DE LOS ESTADOS UNIDOS PARA EL DESARROLLO INTERNACIONAL (USAID)}

Agencia de los Estados Unidos para el Desarrollo InternaCIONAL (USAID) (2004). Estudio legislativo comparado de la carrera judicial. Agencia de los Estados Unidos para el Desarrollo Internacional, Iris Center Perú. Lima: USAID-Iris Center Perú.

\section{BANCO INTERAMERICANO DE DESARROLLO (BID)}

Banco Interamericano de Desarrollo (BID) (1993). Justicia y desarrollo en América Latina y el Caribe. Washington D. C.: BID. (2005). Programa de Mejoramiento de Acceso a la Justicia n. ${ }^{\circ}$ 1061-OC-PE. Washington D. C.: BID.

Cordovez, Carlos (ed.) (2007). Justicia. Un vínculo pendiente entre Estado, ciudadanía y desarrollo. Washington D. C.: BID.

Eyzaguirre, Hugo (1996). Instituciones y desarrollo económico: reforma judicial en América Latina. Documento de trabajo n. ${ }^{\circ}$ 103. Washington D. C.: BID.

JARquín, Edmundo y CARrillo, Fernando (eds.) (1997). La economía política de la reforma judicial. Nueva York: BID.

Thompson, José (coord.) (2000). Acceso a la justicia y equidad. Estudio en siete países de América Latina. San José: BID/ Instituto Interamericano de Derechos Humanos. 


\section{BANCO MUNDIAL (BM)}

Banco Mundial, Banco Interamericano de Desarrollo y Departamento para el Desarrollo Internacional Del Gobierno Británico (2009). Analizando los presupuestos judiciales de la Región Andina. Lima: BM/Banco Interamericano de Desarrollo y Departamento para el Desarrollo Internacional del Gobierno Británico.

Dakolias, María (1997). El sector judicial en América Latina y el Caribe. Washington D. C.: BM.

\section{CENTRO DE ESTUDIOS DE JUSTICIA DE LAS AMÉRICAS (CEJA)}

CABEzón, Andrea (coord.) (2008). Justicia civil: perspectivas para una reforma en América Latina. Santiago: CEJA. (2010). Reformas de la justicia en América Latina. Santiago: CEJA.

DeShazo, Peter y Vargas, Juan Enrique (2005). Reforma judicial en América Latina. Resultados. Washington D. C./Santiago: Centro de Estudios Estratégicos e Internacionales (CSIS) y CEJA.

DucE, Mauricio (ed.) (2005). Reformas procesales penales en América Latina: experiencias de innovación. Santiago: CEJA.

PÁsAra, Luis (2002). Cambios en el sistema de justicia y sociedad civil. Informe comparativo. Lima: CEJA.

PÁsAra, Luis et al. (2003). Justicia y sociedad civil. El papel de la sociedad civil en la reforma judicial: estudios de casos en Argentina, Chile, Perú y Colombia. Santiago: CEJA.

Solano, Montserrat (2004). El acceso a la información judicial en Perú, Chile y Argentina. Santiago: CEJA.

VArgas, Juan Enrique (ed.) (2007). Nueva justicia civil para Latinoamérica: aportes para la reforma. Santiago: CEJA. 
CENTRO PARA LA ADMINISTRACIÓN DE JUSTICIA DE LA UNIVERSIDAD INTERNACIONAL DE LA FLORIDA (CAJ-FIU)

Rico, José Ma. y Salas, Luis (1990a). Independencia judicial en América Latina: replanteamiento de un tema tradicional. Colección Monografías n. ${ }^{\circ}$ 1. San José-Miami: CAJ-FIU.

(1990b). Carrera judicial en América Latina. Colección Monografías n. ${ }^{\circ}$ 2. San José-Miami: CAJ-FIU.

\section{COMISIÓN ANDINA DE JURISTAS (CAJ)}

Comisión Andina de Juristas (CAJ) (1995). Democracia, derechos humanos y administración de justicia en la región andina. Lima: CAJ.

(1998). Reforma y modernización de la administración de justicia en la región andina. Lima: CAJ.

(2002). La sombra de la corrupción: informe anual sobre la región andina. Lima: CAJ.

Cóndor Chuquiruna, Eddie (coord.) (2009). Estado de la relación entre justicia indígena y justicia estatal en los países andinos. Estudios de casos en Colombia, Perú, Ecuador y Bolivia. Lima: CAJ.

(2010). Experiencias y cooperación entre sistemas jurídicos en la región andina. Lima: CAJ.

Eguiguren Praeli, Francisco (coord.) (2000). La reforma judicial en la región andina. ¿Qué se ha hecho, dónde estamos, adónde vamos? Lima: CAJ.

\section{CONSEJO LATINOAMERICANO DE DERECHO Y DESARROLLO}

Belaúnde, Javier de (ed.) (1984). La administración de justicia en América Latina. Lima: Consejo Latinoamericano de Derecho y Desarrollo. 


\section{CORPORACIÓN DE PROMOCIÓN UNIVERSITARIA (CPU)}

Corporación de Promoción Universitaria (CPU) (1993). Reformas procesales en América Latina: la oralidad en los procesos. Santiago: CPU.

Haeussler, María Josefina (1993). Experiencias comparadas de formación judicial. Santiago: CPU.

\section{CORPORACIÓN EXCELENCIA EN LA JUSTICIA (CEJ)}

Corporación Excelencia en la Justicia (CEJ) (1997). Diez pecados de la reforma judicial en América Latina. Bogotá: CEJ.

Fuentes Hernández, Alfredo (ed.) (1999). Reforma judicial en América Latina. Una tarea inconclusa. Bogotá: CEJ.

\section{CUMBRE JUDICIAL IBEROAMERICANA}

Atienza, Manuel y Vigo, Rodolfo Luis (2006). Código Iberoamericano de Ética Judicial. Buenos Aires: La Ley.

\section{FUNDACIÓN INTERNACIONAL PARA SISTEMAS ELECTORALES (IFES)}

Fundación Internacional para Sistemas Electorales (IFES) y Agencia de los Estados Unidos para el Desarrollo INTERNACIONAL (USAID) (2002). Pautas para promover la independencia y la imparcialidad judicial. Washington D. C.: IFES/USAID.

Henderson, Keith et al. (2003). Barreras para la ejecución de decisiones judiciales y el Estado de derecho. Washington D. C.: IFES. 


\section{FUNDACIÓN PARA EL DEBIDO PROCESO LEGAL (DPLF)}

Fundación para el Debido Proceso legal (DPlF) (2002). Iniciativas de la sociedad civil para la transparencia en el sector judicial. Washington D. C.: DPLF.

(2005). Sociedad civil y reforma judicial en América Latina. Foundation and National Center for State Courts. Washington D. C.: DPLF.

\section{INSTITUTO DE DEFENSA LEGAL (IDL)}

Ardito, Wilfredo et al. (2005). La justicia de paz en los Andes: estudio regional. Lima: IDL.

BRANDT, Hans-Jürgen y Franco, Rocío (comps.) (2007). Normas, valores y procedimientos en la justicia comunitaria. Estudio cualitativo en comunidades indígenas y campesinas de Ecuador $y$ Perú. Lima: IDL.

\section{INSTITUTO DE ESTUDIOS COMPARADOS EN CIENCIAS PENALES Y SOCIALES (INECIP)}

Instituto de Estudios Comparados en Ciencias Penales y Sociales (INECIP) (2003). Los Consejos de la Magistratura de Argentina, Bolivia, El Salvador, Paraguay y Perú. Buenos Aires: INECIP.

\section{INSTITUTO LATINOAMERICANO DE SERVICIOS LEGALES ALTERNATIVOS (ILSA)}

Burgos Silva, Germán (ed.) (2003). Independencia judicial en América Latina. ¿De quién? ¿Para qué? ¿Cómo? Bogotá: ILSA/ Ediciones Antropos. 


\section{ORGANIZACIÓN DE LAS NACIONES UNIDAS (ONU)}

Organización de las Naciones Unidas (ONU) (1985). Principios básicos relativos a la independencia de la judicatura. Aprobados por el Séptimo Congreso de las Naciones Unidas sobre Prevención del Delito y Tratamiento del Delincuente del 26 de agosto al 6 de septiembre de 1985. Washington D. C.: ONU.

\section{ORGANIZACIÓN DE LOS ESTADOS AMERICANOS (OEA)}

Lovatón Palacios, David (2007). Acceso a la justicia: llave para la gobernabilidad democrática. Informe final del Proyecto Lineamientos y buenas prácticas para un adecuado acceso a la justicia en las Américas. Washington D. C. : OEA.

\section{PODER JUDICIAL (PJ)}

Poder Judicial (2008). La función disciplinaria en la administración de justicia: una visión comparada. Proyecto de Mejoramiento de los Servicios de Justicia. Banco Mundial. Lima: Oficina de Control de la Magistratura.

Salas Villalobos, Sergio (2008). Sistemas judiciales. Visión y análisis comparativo integral de los modelos contemporáneos en el siglo XXI. Proyecto de Mejoramiento de los Servicios de Justicia. Banco Mundial. Lima: Fimart.

SHACK, Nelson (comp.) (2008a). Gestión para resultados en la administración de justicia: experiencias comparadas. Proyecto de Mejoramiento de los Servicios de Justicia. Banco Mundial. Lima: Heral Mol. (2008b). Seminario internacional sobre presupuestos judiciales en la Región Andina. Proyecto de Mejoramiento de los Servicios de Justicia. Banco Mundial. Lima: Fimart. 


\section{PROGRAMA DE LAS NACIONES UNIDAS PARA EL DESARROLLO (PNUD)}

Programa de las Naciones Unidas para el Desarrollo (PNUD) (2005). Manual de políticas públicas para el acceso a la justicia. América Latina y El Caribe. Buenos Aires: INECIP.

\subsection{Bibliografía complementaria}

Almeida Peña, Feliciano (1995). La administración de justicia y el rol de juez civil. Trujillo: Marsol.

Álvarez Miranda, Ernesto (2008). «La vigencia de la separación de poderes en la independencia de la administración de justicia». En Castillo Freyre, Mario (coord.). Libro homenaje a Felipe Osterling Parodi. Volumen II. Lima: Palestra Editores.

Alzamora Valdez, Mario (1975). La Corte Suprema de Justicia en el sesquicentenario de su institución. Lima.

Asociación Civil Círculo de Derecho Administrativo y Boza Dibos, Beatriz (2008). Compendio de jurisprudencia. Ética y responsabilidad profesional del abogado. Lima: Círculo de Derecho Administrativo-Pontificia Universidad Católica del Perú.

Asociación Civil Ius et Veritas y Boza Dibos, Beatriz (2008). Compendio de ensayos. Ética y responsabilidad profesional del abogado. Lima: Ius et Veritas/Pontificia Universidad Católica del Perú.

Bazán Cerdán, Jorge Fernando (2011). El nuevo Código Procesal Penal del 2004 y las rondas campesinas: escenarios de conflictividad y de coordinación. Lima.

Boza Dibos, Beatriz y Chocano Davis, Christian (2008). Exposición de motivos. Proyecto de Código de Ética y responsabilidad 
del profesional del derecho. Lima: Themis-Pontificia Universidad Católica del Perú.

Cabrera Barrantes, Doraly, Cárdenas Krenz, Ronald, Gutiérrez Tocas, Víctor y Sumarriva Gonzáles, Víctor (2007). La universidad y la formación del abogado en el Perú. Serie Documento para Análisis y Debate n. ${ }^{\circ} 10$. Departamento de Ciencias Jurídicas. Lima: Universidad Femenina del Sagrado Corazón.

Chunga lamonja, Fermín G. y Chunga Chávez, Carmen Flor de María (1998). La justicia de paz en el Perú: manual para jueces de paz. Lima: Grijley.

Donayre Montesinos, Christian (2004). La reforma de la justicia militar. Lima: Jurista Editores.

Lovatón Palacios, David (2007). Tribunal Constitucional y reforma de la justicia militar. Colección Derecho PUCP n. ${ }^{\circ} 1$. Lima: Palestra Editores.

Marroquín Mogrovejo, Nimer (1997). Justicia de paz. Manual de jueces de paz. Puno.

Mendiburu Mendocilla, Miguel (2004). La primera Corte de Justicia del Perú Republicano. Trujillo: Papel de Vientos Editores.

Miranda Canales, Manuel (2008). Manual de derecho jurisdiccional peruano. Lima: Ediciones Jurídicas.

Palma Barreda, Dariberto (2006). El rol del juez y la función jurisdiccional. Trujillo: Normas Legales.

Pérez Perdomo, Rogelio (2004). Los abogados de América Latina. Bogotá: Universidad del Externado de Colombia.

Ramos NuñEZ, Carlos (2007). La pluma y la ley. Abogados y jueces en la narrativa peruana. Lima: Fondo Editorial de la Universidad de Lima. 
Yaya Zumaeta, Edilberto y Yaya Zumaeta, Ulises (2001). El derecho disciplinario judicial: marco teórico y práctico. Lima: Gráfica Horizonte.

Zecenarro Mateus, Carlos (2004). Por la autoridad del juez. Lima: Fecat.

Zolezzi Ibarcena, Lorenzo (1982). La profesión de abogado en Lima: una aproximación empírica. Lima: Fondo Editorial de la Pontificia Universidad Católica del Perú.

\section{ACADEMIA DE LA MAGISTRATURA (AMAG)}

Herrera VÁsquez, Ricardo (2000). Función jurisdiccional. Material de enseñanza del Programa de Formación de Aspirantes. Lima: AMAG.

LeÓN PAstor, Ricardo (2006). Manual de redacción de resoluciones. Lima: AMAG.

\section{ACUERDO NACIONAL}

Acuerdo Nacional (2002). Acuerdo Nacional 22 de julio de 2002. Vigésimo Octava Política de Estado: plena vigencia de la Constitución y de los derechos humanos y acceso a la justicia e independencia judicial. Lima: Biblos.

\section{CENTRO DE ESTUDIOS DE DERECHO Y SOCIEDAD (CEDYS)}

BARrig, Maruja (1980). La ley es la ley. La justicia en la literatura peruana. Antología. Lima: Cedys.

Hurtado Pozo, José (1979). La ley «importada». Recepción del derecho penal en el Perú. Lima: Cedys. 


\section{CENTRO NACIONAL DE PLANEAMIENTO ESTRATÉGICO (CEPLAN)}

Centro Nacional de Planeamiento Estratégico (CEPLAN) (2011). Plan Bicentenario. El Perú hacia el 2021. Eje Estratégico 1 sobre justicia (aprobado por el Acuerdo Nacional). Lima: CEPLAN.

\section{COMISIÓN ANDINA DE JURISTAS (CAJ)}

Comisión Andina de Juristas (CAJ) (1996). Materiales de lectura: la justicia y los derechos humanos en los procesos de modernización. Lima: CAJ.

\section{COMISIÓN DE ALTO NIVEL ANTICORRUPCIÓN (CAN)}

Comisión de Alto Nivel Anticorrupción (CAN) (2010). Lineamientos de trabajo de la Comisión de Alto Nivel Anticorrupción del Perú. Lima: CAN/Cooperación Alemana al Desarrollo (GTZ).

\section{DEFENSORÍA DEL PUEBLO}

Defensoría del Pueblo (1998). Lineamientos para la reforma de la justicia militar en el Perú. Serie Informes Defensoriales. Informe n. ${ }^{\circ}$ 6. Lima: Defensoría del Pueblo. (2002). La justicia militar en una etapa de transición: análisis de los proyectos de reforma. Serie Informes Defensoriales. Informe n. ${ }^{\circ}$ 64. Lima: Defensoría del Pueblo.

(2003). ¿Quién juzga qué? Justicia militar vs. justicia ordinaria. El delito de función en la jurisprudencia del Tribunal Constitucional y la Corte Interamericana de Derechos Humanos. Serie Informes Defensoriales. Informe n. ${ }^{\circ}$ 66. Lima: Defensoría del Pueblo.

(2009). Justicia militar e independencia judicial en el Perú. Normatividad, jurisprudencia y labor de la Defensoría del 
Pueblo. Serie Documentos Defensoriales. Documento n. ${ }^{\circ} 6$. Lima: Defensoría del Pueblo.

\section{PODER JUDICIAL (PJ)}

Aмвía, Abel (2000). Guía de pautas metodológicas para la elaboración de sentencias. Lima: Comisión Ejecutiva del Poder Judicial.

Chunga lamonja, Fermín (1983). La justicia de paz en el Perú. La administración de la justicia de paz (juzgados de paz no letrados). Lima: Sesator.

Poder Judicial (1905). Proyecto de la Corte Suprema de Justicia sobre reforma del código de justicia militar. Lima: Poder Judicial.

(1968). Trujillo. Cuna del Poder Judicial del Perú independiente. Trujillo: Universidad Nacional de Trujillo y Corte Superior de Justicia de La Libertad.

(1975). Sesquicentenario de su instalación 1825-1975. Corte Suprema de Justicia. Lima: Poder Judicial.

(2009). Compendio: Ley Orgánica del Poder Judicial y normas históricas. Lima: Poder Judicial.

Talavera Elguera, Pablo (comp.) (2000). Compendio de derecho judicial. Consejo de Coordinación Judicial, Poder Judicial, Ministerio Público, Academia de la Magistratura, Consejo Nacional de la Magistratura. Cuadernos de Debate Judicial. Normatividad y jurisprudencia. Lima: Consejo de Coordinación Judicial.

\subsection{Bibliografía complementaria a nivel constitucional e histórico}

Alayza, Ernesto (1972). La realidad social y el funcionamiento de las instituciones políticas de la Constitución peruana de 1933. Lima: Pontificia Universidad Católica del Perú. 
Alayza y Paz Soldán, Toribio (1928). Derecho constitucional y general del Perú. Lima: Empresa Editora Cervantes.

Alzamora Silva, Lizardo (1942). La evolución política y constitucional del Perú independiente. Lima: Librería e Imprenta Gil. (1944). Programa razonado de Derecho Constitucional del Perú. Primera parte. Historia Constitucional del Perú. Lima: Imprenta Gil.

BAsadre, Jorge (2010). Perú independiente. Biblioteca Imprescindibles Peruanos. Lima: El Comercio.

Benavides Loredo, Alfonso (1916). Bosquejo sobre la evolución político-jurídico del Perú. Lima.

Bernales, Enrique y Rubio, Marcial (1981). Perú: Constitución y sociedad política. Lima: Desco.

(1996). La Constitución de 1993: análisis comparado. Lima: Konrad-Adenauer Stiftung.

Chanamé Orbe, Raúl (2009). Comentarios a la Constitución. Lima: Jurista Editores.

(2011). La Constitución comentada. 2 tomos. Arequipa: Adrus.

Chirinos Soto, Enrique (1991). Cuestiones constitucionales 19331990. Lima: Fundación M. J. Bustamante de la Fuente.

Chirinos Soto, Enrique y Chirinos Soto, Francisco (1994). Constitución de 1993. Lectura y comentarios. Lima: Empresa Editorial Piedul.

Domínguez Haro, Helder (2008). Derecho a la democracia.

Repensando un modelo societario constitucional. Lima: Grijley.

García Belaunde, Domingo (2006). Las Constituciones del Perú. 2 tomos. Lima: Fondo Editorial de la Universidad San Martín de Porres. 
García Belaunde, Domingo y Planas, Pedro (1993). La Constitución traicionada. Páginas de historia reciente. Lima: Seglusa.

García Toma, Víctor (1998). Análisis sistemático de la Constitución peruana de 1993. 2 tomos. Lima: Fondo de Desarrollo Editorial de la Universidad de Lima.

Hakansson Nieto, Carlos (2009). Curso de derecho constitucional. Lima: Palestra Editores.

Herrera Paulsen, Darío (1987). Derecho constitucional e instituciones políticas. Lima: EDDILI.

Olaechea, Guillermo U. (1922). La Constitución del Perú, dada por la Asamblea Nacional de 1919. Comentada, anotada y concordada con las leyes plebiscitarias y decretos que tienen fuerza de ley, leyes orgánicas, decretos, reglamentos y resoluciones referentes a ellas hasta 1922. Publicación oficial. Lima: Imprenta Americana.

Palomino Manchego, José F. (2003). Problemas escogidos de la Constitución de 1993. México: UNAM-Instituto de Investigaciones Jurídicas.

Pareja Paz-Soldán, José (1954). Las constituciones del Perú (exposición, crítica y textos). Madrid: Ediciones Cultura Hispánica.

(1963). «Evolución constitucional del Perú en el siglo XX». En Pareja Paz-Soldán, José (dir.). Visión del Perú en el siglo XX. Tomo II. Lima: Librería Studium.

(1984). Derecho constitucional peruano y la Constitución de 1979, apreciaciones y comentarios. Lima: Ediciones Justo Valenzuela.

(2005). Historia de las constituciones nacionales (1812-1979).

Lima: Fondo Editorial de la Pontificia Universidad Católica del Perú. 
Pareja Pflücker, Piedad (1989). Justicia y Constitución: la administración de justicia en la Constitución de 1979. Lima: Centro de Estudios Peruanos.

Quispe Correa, Alfredo (2003). La Constitución peruana. Lima: Gráfica Horizonte.

Rubio Correa, Marcial (1999). Estudio de la Constitución Política de 1993. 6 volúmenes. Lima: Fondo Editorial de la Pontificia Universidad Católica del Perú.

Ruiz-Eldredge, Alberto (1980). La Constitución comentada de 1979. Lima: Atlántida.

Torres y Torres Lara, Carlos (2000). El centro del debate constitucional en 1993. 2 tomos. Lima: Fondo Editorial del Congreso del Perú.

Ugarte del Pino, Juan Vicente (1978). Historia de las constituciones del Perú. Lima: Andina.

Villarán, Manuel Vicente (1998). Lecciones de derecho constitucional. Lima: Fondo Editorial de la Pontificia Universidad Católica del Perú.

\section{ASAMBLEA CONSTITUYENTE DE 1978-1979}

Asamblea Constituyente de 1978-1979 (1978). Diario de los Debates de la Asamblea Constituyente 1978-1979. 7 volúmenes. Lima.

\section{ASAMBLEA NACIONAL DE 1919}

Asamblea Nacional de 1919 (1919a). Proyecto de reforma de la Constitución del Perú presentando por la Comisión de Constitución. Lima. (1919b). Diario de los Debates de la Asamblea Nacional de 1919. 2 volúmenes. Lima: Imprenta Torres Aguirre. 


\section{COMISIÓN ANDINA DE JURISTAS (CAJ)}

Eguiguren Praeli, Francisco José (ed.) (1990). Los retos de una democracia insuficiente: diez años de régimen constitucional en el Perú 1980-1990. Lima: CAJ/Fundación Friedrich Naumann.

\section{CONGRESO CONSTITUYENTE DE 1931}

Congreso Constituyente de 1931 (1931-1933). Diario de los Debates del Congreso Constituyente de 1931. 11 tomos. Lima.

\section{CONGRESO CONSTITUYENTE DEMOCRÁTICO (CCD)}

Congreso Constituyente Democrático (1998). Debate Constitucional. Pleno-1993. 3 tomos. Lima: Congreso de la República.

(2001). Diario de los debates. Debate constitucional 1993. Comisión de Constitución y Reglamento. 5 tomos. Lima: Congreso de la República. 


\section{ANEXO}

\section{Área de Transformaciones Orgánicas}

Proyecto de Ley n. ${ }^{\circ} 3292 / 2008-P J$

Instaura el Sistema de Medición del Desempeño Jurisdiccional que sustituye el Subcapítulo II del Capítulo III del Título V de la Ley de la Carrera Judicial.

Proyecto de Ley n. ${ }^{\circ}$ 0426/2011-PJ

Otorgan facultades extraordinarias frente a situaciones de carácter excepcional, creación de la Corte Superior Nacional, reforma a los ámbitos de gobierno y de organización del Poder Judicial.

Proyecto de Ley n. ${ }^{\circ}$ 1745/2017-PJ

Reforma del artículo 145 de la Constitución Política del Perú, asignación presupuestaria no inferior al $4 \%$ del Presupuesto General de la República.

Proyecto de Ley n. ${ }^{\circ}$ 1862/2017-PJ

Proyecto de Ley de la Carrera del Trabajador Judicial.

Proyecto de Ley n. ${ }^{\circ}$ 2902/2017-PJ

Reforma Constitucional de los artículos 154, 155 y 156 de la Constitución Política del Perú y los artículos 2, 5, 6, 17, 19, 21, 42 y Segunda Disposición Transitoria y Final de la Ley Orgánica del Consejo Nacional de la Magistratura.

Proyecto de Ley n. ${ }^{\circ}$ 3430/2018-PJ

Ley que modifica el mecanismo de elección del presidente de la Corte Suprema de Justicia de la República, elegido entre todos los jueces titulares del país por mayoría absoluta; y de presidentes de las Cortes Superiores de Justicia, elegidos entre todos los jueces titulares del distrito judicial respectivo, por mayoría absoluta. 


\section{Área de Lucha contra la Corrupción}

Proyecto de Ley n. ${ }^{\circ}$ 0427/2011-PJ

Modifica los artículos 102 y 103 de la Ley Orgánica del Poder Judicial, y el artículo 48 de la Ley de Carrera Judicial que crea la especialidad de jueces contralores.

Proyecto de Ley n. ${ }^{\circ}$ 3316/2018-PJ

Ley que incorpora el numeral 10 en el artículo 80 del Texto Único Ordenado de la Ley Orgánica del Poder Judicial, que otorga a la Sala Plena de la Corte Suprema de Justicia la atribución extraordinaria para apartar temporalmente a jueces supremos titulares o provisionales o consejeros del Consejo Ejecutivo de la función jurisdiccional o de gobierno.

Proyecto de Ley n. ${ }^{\circ}$ 3602/2018-PJ

Ley que crea la Autoridad Nacional de Integridad y Control del Poder Judicial.

\section{Área de Modificaciones a la Legislación Procesal}

Proyecto de Ley n. ${ }^{\circ}$ 0313/2011-PJ

Ley de Coordinación Intercultural de la Justicia.

Proyecto de Ley n. ${ }^{\circ} 3732 / 2014-P J$

Ley General de Casación Civil y Contencioso Administrativa.

Proyecto de Ley n. ${ }^{\circ}$ 3989/2014-PJ

Modificación del artículo 141 de la Ley Orgánica del Poder Judicial, celeridad en las causas en materia laboral y de seguridad social.

Proyecto de Ley n. ${ }^{\circ}$ 1746/2017-PJ

Ley que modifica el artículo VII del Título Preliminar y los artículos 12, 14, 27, 28, 42, 51, 53 y Tercera Disposición Final del Código Procesal Constitucional, así como diversos artículos de la Ley Orgánica del Poder Judicial: calidad de precedente constitucional 
de las decisiones de la Corte Suprema de Justicia en procesos de acción popular, competencia territorial y competencia funcional, y demandas constitucionales de la libertad en idioma originario del justiciable.

Proyecto de Ley n. ${ }^{\circ} 1861 / 2017-P J$

Ley que regula la implementación de la justicia itinerante para el acceso a la justicia de personas en condición de vulnerabilidad.

Fuente: Unidad de Investigaciones y Fondo Editorial del Centro de Investigaciones Judiciales del Poder Judicial. 